C. Eberle, P. Gerlinger, M. Aigner, A sectional PAH model with reversible PAH chemistry for CFD soot simulations, Combustion and Flame 179 (2017) 63-73

The original publication is available at www.elsevier.com

http://dx.doi.org/10.1016/j.combustflame.2017.01.019 


\section{A Sectional PAH Model with Reversible PAH Chemistry for CFD Soot Simulations}

Authors: C. Eberle ${ }^{a}$, P. Gerlinger ${ }^{b}$, M. Aigner ${ }^{a}$

\section{Affiliations:}

a Institut für Verbrennungstechnik, Deutsches Zentrum für Luft- und Raumfahrt, Paffenwaldring 38-40, 70569 Stuttgart, Germany

$b$ Institut für Verbrennungstechnik der Luft- und Raumfahrt, Universität Stuttgart, Paffenwaldring 38-40, 70569 Stuttgart, Germany

\section{Corresponding Author:}

Christian Eberle

Institut für Verbrennungstechnik

Deutsches Zentrum für Luft-und Raumfahrt (DLR)

Pfaffenwaldring 38-40, 70569 Stuttgart, Germany

Phone: $+49 / 711 / 6862-563$, Fax: $+49 / 711 / 6862-578$

Email: christian.eberle@dlr.de

Type of Article: Full Length Article

Short title: A PAH Model for CFD Soot Simulations

Keywords: polycyclic aromatic hydrocarbons (PAHs); reduced PAH chemistry; sectional approach; soot; particle size distribution 


\title{
A Sectional PAH Model with Reversible PAH Chemistry for CFD Soot Simulations
}

\author{
C. Eberle, P. Gerlinger, M. Aigner
}

\begin{abstract}
A novel sectional approach for the modeling of polycyclic aromatic hydrocarbons (PAHs) is presented. The PAH model includes PAH radicals and is based on a reversible PAH growth mechanism. Combustion of species up to benzene and toluene is treated by finite-rate chemistry. The soot particle size distribution (PSD) is discretized by a sectional approach. Soot, PAHs, and the thermo-chemical state of the gas phase are fully coupled by a simultaneous solution of all governing equations. The new PAH model has been validated for a series of combustion configurations and shows significant improvements compared to irreversible PAH models at basically no increase in computational cost. Compared to irreversible PAH models, soot nucleation is significantly slower, yielding a better agreement to measured soot volume fractions in a series of laminar premixed flames. Moreover, the model developments led to correct predictions of the temperature dependency of the soot yield in ethylene pyrolysis after reflected shock waves. Finally, it will be shown that the new model describes the influence of the equivalence ratio on soot PSD functions correctly.
\end{abstract}

Keywords polycyclic aromatic hydrocarbons (PAHs); reduced PAH chemistry; sectional approach; soot; particle size distribution

\section{Introduction}

Soot predictions are a pressing technological need. This is not only due to adverse effects on health, environment, and climate [1, 2, 3, 4] but also from an engineering point of view. An example are 
aero-engine combustors where soot, by its high radiative emissivity, contributes to locally elevated heat loads on combustion chamber walls [5]. Soot modelling in technical combustion devices as for example gas turbine combustors or internal combustion engines by means of computational fluid dynamics (CFD) is a challenging task. On one hand, complex geometries impose high computational cost, since in many applications grids with several million volumes are required for an accurate spatial resolution [6]. To allow realistic simulation times under such circumstances, a soot model for CFD applications can only consider the most important processes of soot evolution using as few variables as possible. On the other hand, technical combustion usually occurs at high pressures and temperatures and is very complex, since effects such as turbulence, partial premixing, and secondary air injection may lead to locally and temporally varying combustion conditions. For accurate soot predictions in such complex systems, the soot model has to be validated for a wide range of different combustion problems.

One of the least understood processes of soot evolution is nucleation. In simple nucleation models, nucleation rates are correlated to the acetylene concentration [7]. Because such models are computationally efficient, they are nowadays often used for simulations of complex combustion configurations as for example turbulent jet flames [8, 9], gas turbine combustors [10] or diesel engines [11]. A recent study by Roy and Haworth [12] confirmed that good soot predictions can be obtained with such models. However, as shown by McKinnon and Howard [13], exclusive formation of nascent soot by acetylene addition can be too slow. Moreover, the fast depletion of PAHs in regions where soot is formed shows that soot nucleation is correlated to PAH distributions [13, 14, 15, 16, 17.

Therefore, more comprehensive soot models which include a detailed description of PAH kinetics have been developed and applied to laminar combustion problems. In these models, soot nucleation is modeled by PAH dimerization. Either a single PAH species as for example pyrene [18, 19] or an ensemble of PAH species [20, 21] are used as soot incipient species. However, since the number of species with similar mass and the number of structural isomers increase quickly with molecular mass [22], lumping techniques for PAHs exceeding a certain size have been developed [22, 23]. These PAH models distinguish between PAH molecules and PAH radicals and PAH kinetics are described in a detailed way. In recently published sectional PAH models [24, 25] an additional 
discretization for the $\mathrm{H} / \mathrm{C}$-ratio of PAHs is introduced to distinguish between different molecule structures. An example is the model of D'Anna et al. [24] where species heavier than $300 \mathrm{~g} / \mathrm{mol}$ are discretized by 25 mass classes and five subclasses with different H/C-ratios are introduced per class. In total $125(5 \mathrm{H} / \mathrm{C}$ ratios $\times 25$ mass classes $)$ lumped species are defined in this way for PAH molecules and another 125 for the corresponding PAH radicals. Eaves et al. [26] and Veshkini et al. 27] developed models which consider the reversibility of soot nucleation and PAH condensation processes. For the calculation of the respective reverse rates, additional transport equations for PAHs on the soot surface were introduced. Thereby the need for arbitrary constants for nucleation and condensation efficiencies was removed.

Due to the high computational cost of such complex approaches, different model reduction strategies have been developed for PAH chemistry to be used in turbulent flame simulations. One possibility are flamelet combustion models which rely on tabulated chemistry. Pitsch et al. [28] developed a Lagrangian unsteady flamelet approach where equations for the kinetics of gas phase species up to pyrene, the further planar PAH growth, and a two moment soot model are interactively solved in mixture fraction space. In a later work, Mueller et al. [29] used a steady flamelet/progress variable model [30] for large-eddy simulations of a sooting turbulent jet flame. Since PAH mass fractions can deviate significantly from the steady state flamelet model [31], Mueller et al. [29] implemented an additional transport equation for a single lumped PAH species to take the slow PAH chemistry into account. An extended PAH relaxation model for flamelet simulations was developed in a later work by Xuan and Blanquart [32]. This model includes multi-step chemical processes of PAHs by solving transport equations for benzene and naphthalene. While these PAH models take the slow time scales of PAH kinetics into account, they do not provide information about the PAH size distribution and PAH radicals are not explicitly considered. However, as will be shown in this work, both aspects can be relevant to obtain correct soot nucleation rates and ultimately accurate predictions of the soot morphology. Besides these flamelet based approaches, reduced PAH models which are solved directly by finite-rate chemistry were developed [33, 34, 35]. They are computationally more expensive but provide a full coupling of soot, PAHs, and the thermochemical state of the gas phase by a simultaneous solution of all governing equations. These finiterate chemistry based models use skeletal mechanisms to describe the formation of small aromatic 
species, as for example benzene. PAH chemistry is modeled in a simplified way by irreversible reactions between a few lumped PAH species. Basis of this work is a sectional PAH model of Blacha et al. [35], where PAHs with a molar weight in the range of $100 \mathrm{~g} / \mathrm{mol}$ to $800 \mathrm{~g} / \mathrm{mol}$ are discretized by three sections. In this model, PAH radicals are not considered and irreversible PAH chemistry is assumed. The model has been validated using different laminar [35] and turbulent [36] flames where a good overall agreement was found with one set of model constants. However, this model has difficulties in combustion regimes with strong partial premixing. For example, it cannot correctly predict the sensitivity of particle size distribution (PSD) functions with respect to the equivalence ratio at conditions close to the sooting limit in a plug flow reactor. Also, as a result of a too fast PAH growth, the onset of soot formation is predicted too early in laminar premixed flames. Moreover, coupled to a two-equation soot model [34] and used for simulations of a confined swirl flame [37], the maximum soot volume fraction is significantly overpredicted [6]. This is attributed to the cited challenges regarding partial premixing and irreversible PAH chemistry.

Thus the focus of the present work is the development of a new PAH model in order to improve the predictive capability of soot models at technically relevant conditions. To this end PAH radicals and a reversible formulation of PAH chemistry are introduced. The model will be validated for selected combustion configurations which capture technical relevant aspects such as elevated pressures, high temperatures, and partial premixing. Comparisons to an irreversible PAH model [35] and to more detailed models from the literature will be presented and differences will be analyzed.

\section{Methodology}

The soot and PAH models are implemented in the DLR code THETA. THETA is an unstructured finite-volume solver which has been optimized for low Mach number combustion problems. Combustion is modelled by finite-rate chemistry. PAHs and soot are described by sectional approaches where transport equations are solved for each section. Chemical reactions involving soot and PAHs are formulated in Arrhenius form and are solved in the same way as reactions of gas phase species. This allows a full coupling of soot, PAHs, and gas phase species. The calculation of diffusion coefficients [38] is based on molecular data as derived in [39]. Diffusive fluxes of soot sections are set to 
zero due the large Schmidt number of soot particles $(1 / \mathrm{Sc} \rightarrow 0)$, while thermophoresis [40] of soot particles is taken into account [35].

\subsection{Gas Phase Chemistry}

The kinetics of gas phase species are modeled by a reaction mechanism which describes the formation of hydrocarbons up to benzene and toluene. The mechanism includes 43 species and 304 elementary reactions and has been validated for pyrolysis and combustion of small hydrocarbons, such as methane or ethylene at atmospheric and high-pressure conditions [41]. This mechanism has been obtained by reduction of the detailed mechanism of Slavinskaya et al. [20] and has successfully been used for soot predictions in previous works [ㅁ, 35, 36].

\subsection{PAH Model}

As shown in Fig. 1, PAHs are described by three logarithmically scaled sections. The minimum PAH mass is set to $100 \mathrm{~g} / \mathrm{mol}$ in order to cover all PAHs (Naphthalene being the smallest PAH has a molar mass of $128 \mathrm{~g} / \mathrm{mol}$ ). As the maximum PAH mass is assumed to be equal to the minimum soot mass (cf. Fig. 1), the maximum PAH mass has to be chosen in a way to yield incipient soot particles of realistic size. At the same time the maximum PAH mass should be as small as possible. This is because modelling uncertainties may increase with increasing PAH size since, as will be shown in section 2.2.2, chemical analogy to small PAHs is assumed. Also, as will be discussed in section 2.2.1, thermodynamical data may not be available for very large PAHs. In this context, it was decided to set the maximum PAH mass to $800 \mathrm{~g} / \mathrm{mol}$ leading to an incipient soot particle diameter of $1.28 \mathrm{~nm}$ which is in line with measured particle diameters [42]. To describe reversible PAH chemistry, a radical branch $\mathrm{PAH}_{i}^{*}$ is assigned to each $\mathrm{PAH}$ section.

\subsubsection{PAH Thermodynamics}

Thermodynamic properties such as $\mathrm{H} / \mathrm{C}$ ratios and enthalpies of $\mathrm{PAH}_{i}$ are obtained by inter- and extrapolation from 43 reference PAHs [43] ranging from benzene to tetrabenzoperylene as explained in [35]. Transport properties of $\mathrm{PAH}_{i}$ are obtained in a similar way using data from Richter et 
al. [22]. While it is assumed that transport properties of $\mathrm{PAH}_{i}^{*}$ are identical to those of $\mathrm{PAH}_{i}$, an approximation for the enthalpy of PAH radicals is required. As shown in Fig. 2 on the basis of pyrene, the enthalpy difference between a PAH molecule and the corresponding PAH radical

$$
\Delta h^{*}=h_{\mathrm{PAH}_{i}^{*}}-h_{\mathrm{PAH}_{i}}
$$

is approximately constant. An analysis of a number of unsubstituted PAHs ranging from naphthalene to ovalene using thermodynamic data from Burcat et al. [44] and Richter et al. [45] showed that $\Delta h^{*}$ is not a function of the PAH size. Using $\Delta h^{*}=2.5 \times 10^{5} \mathrm{~J} / \mathrm{mol}$, the maximum deviation between $h_{\mathrm{PAH}^{*}}$ derived from thermodynamic data [44, 45] and $h_{\mathrm{PAH}^{*}}$ calculated by Eq. (1) is approximately $5 \%$ in the temperature range $500 \mathrm{~K}<T<3000 \mathrm{~K}$. This is considered reasonably accurate for the calculation of mixture properties such as temperatures. The fitted thermodynamical data of PAH sections should however not be used to calculate equilibrium constants since fitting errors may be amplified exponentially [35]. Moreover, the concentration of $\mathrm{PAH}_{i}^{*}$ is low compared to $\mathrm{PAH}_{i}$ (see section 3.1). Thus, the influence of PAH radicals on the enthalpy of the mixture is expected to be small.

\subsubsection{PAH Chemistry}

PAH chemistry is divided into four processes: $\mathrm{PAH}_{1}$ gas phase interaction, $\mathrm{PAH}$ dehydrogenation, acetylene $\left(\mathrm{C}_{2} \mathrm{H}_{2}\right)$ addition, and $\mathrm{PAH}$ oxidation. The chemical kinetics describing these processes are defined in analogy to small PAHs. A list of the individual chemical reactions is given in table 1 . Rate parameters are taken from a detailed reaction mechanism which describes the kinetics of PAHs up to benzo(a)pyrene [46]. Since the fitted thermodynamical data of PAH sections should not be

used to calculate equilibrium constants (cf. section 2.2.1), reverse rates are also taken from small PAHs. As this simple approximation may induce some uncertainty, parametric sensitivity studies will be shown in the supplemental material. The stoichiometric coefficients $\nu$ are introduced to satisfy mass conservation.

$\mathrm{PAH}_{1}$ gas phase interaction describes the formation and consumption of $\mathrm{PAH}_{1}$ by reactions with chemical species included in the gas phase mechanism (for instance benzene or toluene). Blacha et 
al. [35] derived 19 reversible reactions for $\mathrm{PAH}_{1}$ gas phase interaction. In the present work, this set of reactions is extended by 6 reactions (see table 1) which additionally describe the interaction of gas phase species with the $\mathrm{PAH}_{1}^{*}$ radical. They are taken from the mechanism of Slavinskaya et al. [46].

Dehydrogenation or H-atom abstraction is the first step of the hydrogen-abstraction acetyleneaddition (HACA) mechanism [47]. In the present approach, dehydrogenation of PAHs by H-atoms, O-atoms, hydroxyl $(\mathrm{OH})$, and unimolecular decomposition is considered. The corresponding reaction rates (see table 1) are taken from equivalent PAH reactions as defined in [46]. The second step of the $\mathrm{HACA}$ mechanism is $\mathrm{C}_{2} \mathrm{H}_{2}$ addition at a reactive site of a $\mathrm{PAH}$ radical. The newly developed reversible formulation of $\mathrm{C}_{2} \mathrm{H}_{2}$ addition is given by:

$$
\begin{aligned}
\mathrm{PAH}_{j}^{*}+\mathrm{C}_{2} \mathrm{H}_{2} & \rightarrow \nu_{1} \mathrm{PAH}_{j}+\nu_{2} \mathrm{PAH}_{j+1}+\nu_{3} \mathrm{H}, \\
\mathrm{PAH}_{j}+\mathrm{H} & \rightarrow \nu_{1} \mathrm{PAH}_{j-1}^{*}+\nu_{2} \mathrm{PAH}_{j}^{*}+\nu_{3} \mathrm{H}_{2}+\mathrm{C}_{2} \mathrm{H}_{2} .
\end{aligned}
$$

Following Pope an Howard [48, the stoichiometric coefficients $\nu_{i}$ are calculated depending on intra sectional distribution functions and atom conservation. This is done in a way that both, mass and atoms are conserved (see [35] for more details). This procedure is also applied in case of PAH oxidation and PAH collisions. The reaction rate parameters for the $\mathrm{C}_{2} \mathrm{H}_{2}$ addition are obtained by assuming chemical analogy to the pyrene radical [46]. Further considerations are required for $\mathrm{C}_{2} \mathrm{H}_{2}$ addition to the last PAH section $(j=3$ in Eq. [2]). In this case, Blacha et al. [35] replaced $\mathrm{PAH}_{j+1}$ by $\mathrm{SOOT}_{1}$ and thereby allowed $\mathrm{C}_{2} \mathrm{H}_{2}$ addition to contribute to soot nucleation. This is in contrast to soot models with detailed PAH chemistry, where soot nucleation is modelled by PAH dimerization [18, 22, 49]. Therefore $\nu_{2}$ is set to zero for $j=3$ and in this case Eq. (2) reads $\mathrm{PAH}_{3}^{*}+\mathrm{C}_{2} \mathrm{H}_{2} \rightarrow \nu_{1} \mathrm{PAH}_{3}+\nu_{3} \mathrm{H}$. Oxidation of PAHs is implemented in a similar way. An example is the PAH oxidation by molecular oxygen

$$
\mathrm{PAH}_{j}^{*}+\mathrm{O}_{2} \rightarrow \nu_{1} \mathrm{PAH}_{j-1}^{*}+\nu_{2} \mathrm{PAH}_{j}^{*}+\nu_{3} \mathrm{H}_{2}+2 \mathrm{CO}
$$

Since the transition of PAHs to gas phase species is captured by the $\mathrm{PAH}_{1}$ gas phase interaction 
model, $\nu_{1}$ is set to zero in Eqs. (3) and (4) for $j=1$. The full list of PAH oxidation reactions is given in table 1 .

\subsubsection{PAH Collisions and Condensation}

The collision source term is given in general form by

$$
\omega_{i, j}=2.2 \gamma_{i, j} \beta_{i, j}\left[\mathrm{BIN}_{i}\right]\left[\mathrm{BIN}_{j}\right]
$$

where 2.2 is the van der Waals enhancement factor and $\mathrm{BIN}_{i}$ is a place holder for either $\mathrm{PAH}_{i}$, $\mathrm{PAH}_{i}^{*}$ or $\mathrm{SOOT}_{i}$. The collision frequency $\beta_{i, j}$ is calculated using a formulation which applies for the entire Knudsen number range [35, 50]. As will be discussed in the following, different efficiencies $\gamma_{i, j}$ are used depending on the type of collision process. Concerning PAH collisions, it is distinguished between a molecular growth mechanism (where radical sites are required for reaction) and coagulation processes based on collision frequencies from the kinetic theory of gases. The latter do not require radical sites, however low molecular mass compounds have low collision efficiencies [51]. Using a correlation developed by Saggese et al. [25], efficiencies in the order of $10^{-3}$ were obtained for collisions involving $\mathrm{PAH}_{3}$. Due to these low efficiencies, it was decided to consider PAH coagulation to be negligibly slow. This assumption has also been taken by Richter et al. [22] and by Slavinskaya and Frank [20]. PAH coagulation is however taken into account by some PAH models [24, 25] where PAH molecules larger then those in the present work are considered. Collisions between PAH radicals and collisions between PAH radicals and PAH molecules read for $i, j \in[1,3]$ and $k=\max (i, j)$ in global reaction formulation:

$$
\begin{aligned}
& \mathrm{PAH}_{i}^{*}+\mathrm{PAH}_{j}^{*} \rightarrow \nu_{1} \mathrm{PAH}_{k}+\nu_{2} \mathrm{PAH}_{k+1}+\nu_{3} \mathrm{H}_{2}, \\
& \mathrm{PAH}_{i}^{*}+\mathrm{PAH}_{j} \rightarrow \nu_{1} \mathrm{PAH}_{k}+\nu_{2} \mathrm{PAH}_{k+1}+\nu_{3} \mathrm{H}_{2}+\mathrm{H} .
\end{aligned}
$$

As in [52, a unity collision efficiency $\left(\gamma_{i, j}=1\right)$ is assumed. The products of reactions $(6)$ and (7) are PAH molecules and hydrogen is added on the product side to enable atom conservation at a size-dependent $\mathrm{H} / \mathrm{C}$ ratio. The $\mathrm{H}$-atom in reaction (7) ensures conservation of reactive sites. 
Stoichiometric coefficients are calculated in a way that both, mass and atoms are conserved. In contrast to previously published irreversible PAH models [34, 35], collisions between PAH molecules $\left(\mathrm{PAH}_{i}+\mathrm{PAH}_{j} \rightarrow\right.$ products $)$ are not taken into account. Soot nucleation is modeled as a special case of reactions (6) and (7), namely by collisions involving $\mathrm{PAH}_{3}$ or $\mathrm{PAH}_{3}^{*}$ as reactant. In these cases $\mathrm{PAH}_{j+1}$ is replaced by $\mathrm{SOOT}_{1}$ and the reactions read for $1 \leq i \leq 3$

$$
\begin{aligned}
& \mathrm{PAH}_{i}^{*}+\mathrm{PAH}_{3}^{*} \rightarrow \nu_{1} \mathrm{PAH}_{3}+\nu_{2} \mathrm{SOOT}_{1}+\nu_{3} \mathrm{H}_{2} \\
& \mathrm{PAH}_{i}^{*}+\mathrm{PAH}_{3} \rightarrow \nu_{1} \mathrm{PAH}_{3}+\nu_{2} \mathrm{SOOT}_{1}+\nu_{3} \mathrm{H}_{2}+\mathrm{H}
\end{aligned}
$$

The condensation of $\mathrm{PAH}_{i}$ or $\mathrm{PAH}_{i}^{*}$ onto soot particles is given by

$$
\begin{aligned}
& \mathrm{PAH}_{i}+\mathrm{SOOT}_{j} \rightarrow \nu_{1} \mathrm{SOOT}_{j}+\nu_{2} \mathrm{SOOT}_{j+1}+\nu_{3} \mathrm{H}_{2} \\
& \mathrm{PAH}_{i}^{*}+\mathrm{SOOT}_{j} \rightarrow \nu_{1} \mathrm{SOOT}_{j}+\nu_{2} \mathrm{SOOT}_{j+1}+\nu_{3} \mathrm{H}_{2}+\mathrm{H},
\end{aligned}
$$

where $1 \leq i \leq 3$ and $1 \leq j \leq 24$. Based on previous modelling studies [35] a constant collision efficiency $\gamma_{i, j}=0.3$ is assumed for PAH condensation.

\subsection{Soot Model}

In the present work, the sectional soot model developed by Blacha et al. [35] is used. The number of soot sections is governed by the minimum and the maximum soot mass, and by the scaling factor between the masses of subsequent sections $s=M_{i+i} / M_{i}$. Corresponding to the geometric constraint of Gelbard and Seinfeld [53] ( $\mathrm{s} \geq 2), s=2$ has been chosen. While the minimum soot mass is equal to the maximum PAH mass (see section 2.2 and Fig. 1), the maximum soot mass must be chosen large enough to fully resolve the particle size distribution. As in the work of Blacha et al. [35], the particle size distribution is discretized by 25 sections, thereby covering particle diameters from 1.3 nm to $329 \mathrm{~nm}$ (cf. Fig. 1). Simulations using a soot model with 30 bins led to virtually identical results. Therefore, 25 soot sections are considered to be sufficient for the test cases investigated in

this work. Soot nucleation is modeled by PAH growth as described above. Soot surface growth is modelled by addition of $\mathrm{C}_{2} \mathrm{H}_{2}$ and condensation of PAHs. Soot oxidation by $\mathrm{OH}$ and $\mathrm{O}_{2}$ is taken 
into account. Coagulation is considered as described in [35]. The model conserves both, mass and atoms.

\section{Results and Discussion}

A number of experiments is simulated to investigate the newly presented PAH model which includes PAH radicals and reversible PAH chemistry. Results are compared to an older model without these features [35]. The quality of the numerical results is additionally assessed by comparison with results from the literature where different models are used. They are summarized in table 2 and some of them use significantly more detailed chemical mechanisms for combustion and PAH evolution. Assuming that computational cost scales with the number of species squared, the model of Slavinskaya et al. [20] is factor 3.6 more expensive than the present model. If not stated otherwise, the same set of model constants is applied for all simulations.

\subsection{Laminar Premixed Flames}

For model validation in terms of soot volume fractions, a set of laminar premixed flames (LPF) with varying pressures and equivalence ratios is chosen. These flames [54] are ISF (International Sooting Flame Workshop) target flames (ISF-3 Target Flame 4). Experimental investigations include laser induced incandescence (LII) measurements of soot volume fractions with a measurement uncertainty of $\pm 30 \%$ and shifted-vibrational coherent anti-Stokes Raman spectroscopy (SV-CARS)

measurements of temperatures with an measurement uncertainty $\pm 3 \%$ [54]. The consistency of the PAH and soot model concerning the prediction of major species and soot precursors, such as acetylene and benzene, is investigated at an atmospheric ethylene flame with an equivalence ratio of $\phi=3.06$. Comprehensive species data was obtained for this flame by gas chromatography-mass spectrometry (GC-MS) [55]. The estimated measurement uncertainty was reported to be $\pm 15 \%$ for major species, $\pm 20 \%$ for minor species, and at least factor 2 for some of the PAH species shown in the bottom right panel of Fig. 4. The simulations were performed on one-dimensional grids which are refined close to the burner surface to accurately resolve the high axial gradients in this region. The temperature was prescribed by interpolating measured temperature profiles on the 
CFD grid. Modeling uncertainties from the unknown heat flux to the burner surface and from heat radiation are thereby mitigated. Inflow conditions of the flames are summarized in table 3.

As shown in Fig. 3, an excellent agreement between predicted and measured profiles is observed for all species shown. A comparison of measured and calculated soot precursor species is given in Fig. 4. Both, the new model with reversible PAH chemistry and the irreversible PAH model of Blacha et al. [35] agree well with the measured acetylene $\left(\mathrm{C}_{2} \mathrm{H}_{2}\right)$, benzene $(\mathrm{A1})$, and toluene $\left(\mathrm{C}_{7} \mathrm{H}_{8}\right)$ profiles. The reversible PAH model predicts higher concentrations of soot precursor species than the irreversible one. This is due to lower soot growth rates which cause a lower consumption of soot precursor species. This context will be discussed later in more detail by means of the source term analysis in table 4. With respect to benzene, the deviation between the old and the new model is approximately factor two. This shows that feed back effects of soot evolution on the concentration of gas phase species can be significant. The small + signs in the bottom right panel of Fig. 4 denote mole fractions of measured PAHs with a molar weight in the range between 100 and $200 \mathrm{~g} / \mathrm{mol}$ which corresponds to $\mathrm{PAH}_{1}$. Since the mole fractions of these PAHs differ by more than one order of magnitude at any position in the flame, a comparison of predicted $\mathrm{PAH}_{1}$ profiles and measured PAH data is difficult. However, the reversible PAH model reasonably describes the concentration of $\mathrm{PAH}_{1}$ as the predicted profile is in the range of measured $\mathrm{PAH}$ data. The irreversible PAH model on the other hand significantly underpredicts $\mathrm{PAH}_{1}$ since, as will be shown in the following, the consumption of $\mathrm{PAH}_{1}$ by $\mathrm{PAH}$ growth reactions is too fast.

Predicted and measured soot volume fractions $f_{v}$ are shown in Fig. 5 for a series of laminar premixed flames. Both, the reversible and the irreversible model predict the general shape of the soot distribution and the trends of increasing $f_{v}$ with increasing pressure and increasing equivalence ratio well (note the different axis limits between the atmospheric and 3 bar flames). In particular for the atmospheric flames, reversible PAH chemistry yields a delayed soot formation and subsequently a better agreement with the measurements concerning the onset of soot formation and the maximum soot volume fraction. The agreement to measured soot volume fractions is comparable to the model of Slavinskaya et al. [20] where PAHs up to benzo(a)pyrene are resolved by a detailed chemical mechanism and soot is calculated in a post processing step using a modified version [56] of the Frenklach and Wang soot model [47]. 
The differences between reversible and irreversible PAH model are analyzed in more detail by the following study on the basis of the atmospheric LPF with $\phi=2.3$ (results from this flame are representative for the other flames listed in table 3). To this end, Fig. 6 shows predicted mass fractions of PAH sections, PAH radicals, and $\mathrm{SOOT}_{1}$. As shown in the top panel of Fig. 6, the model with irreversible PAH chemistry [35] predicts the mass fractions of PAHs and $\mathrm{SOOT}_{1}$ to peak approximately at the same position. The maximum mass fractions are increasing from $\mathrm{PAH}_{1}$ to $\mathrm{SOOT}_{1}$, indicating that $\mathrm{PAH}_{1}$ is consumed quickly by respective $\mathrm{PAH}$ growth reactions. The reversible PAH model predicts a significantly different PAH size distribution. As a result of a slower PAH growth, $\mathrm{PAH}_{1}$ accumulates and becomes the PAH section with the maximum mass fraction. The larger PAH sections and $\mathrm{SOOT}_{1}$ peak at significantly lower mass fractions and are formed further downstream. This result is in line with the expectation of slow PAH chemistry and there is also experimental evidence that the concentration of small $\mathrm{PAHs}$ (the upper limit of $\mathrm{PAH}_{1}$ is $200 \mathrm{~g} / \mathrm{mol}$ which corresponds approximately to the molar weight of 4-ring PAHs) is significantly higher than that of larger PAHs. For example, Di Lorenzo et al. [57] found that the concentration of 5 to 7 ring PAHs is almost negligible compared to the concentration of smaller PAHs in rich, premixed $\mathrm{CH}_{4} / \mathrm{O}_{2}$ flames. Similar observations were made for the oxidation of toluene and heptane after reflected shock waves [58] and more recently in the pyrolysis of $\mathrm{C}_{2} \mathrm{H}_{4}$ and $\mathrm{C}_{2} \mathrm{H}_{2}$ [59, 60]. The calculated PAH radical profiles shown in the bottom panel of Fig. 6 have a similar shape as the corresponding PAH molecules. Their concentration however is about three orders of magnitude lower which is in line with experimental investigations [61, 62], where the concentration of PAH radicals was measured in laminar premixed flames using nozzle beam sampling followed by radical scavenging with dimethyl disulfide.

As shown in table 4, the different PAH size distributions have significant implications on soot nucleation. With irreversible PAH chemistry [35], the contribution of soot nucleation to the total soot production term is more than $24 \%$ in all investigated flames, while in case of reversible PAH chemistry it is of the order of $0.1 \%$. This is in agreement with experimental and numerical studies of laminar premixed ethylene flames, where nucleation was found to be orders of magnitude lower than surface growth [63, 64, 65, 66]. The percentage of PAH condensation onto soot particles increases with increasing pressure and equivalence ratio. The most extreme case is the atmospheric 
$\phi=3.06$ flame were the contribution of condensation $(61 \%)$ is higher than that of surface growth via $\mathrm{C}_{2} \mathrm{H}_{2}$ addition (39\%).

\subsection{Soot Yield after Reflected Shock Waves}

Vlasov and Warnatz [67] presented measurements and predictions of soot yields (percentage of carbon mass contained in soot particles) in ethylene pyrolysis after reflected shock waves at a pressure of 50 bar for different initial temperatures and carbon concentrations (4.0, 4.7, and 7.4 $\mathrm{mol} / \mathrm{m}^{3}$ carbon atoms in argon). In their model, gas phase chemistry is described by a detailed mechanism (1700 gas phase elementary reactions, 141 species) for PAHs up to pyrene and polyynes up to $\mathrm{C}_{12} \mathrm{H}_{2}$. The soot particle size distribution is approximated by a discrete Galerkin technique suggested by Deuflhard and Wulkow [68]. The shock tube experiments were modelled as adiabatic, isochoric reactors with residence times of $1.5 \mathrm{~ms}$.

A comparison of predicted and measured soot yields as a function of temperature is given in Fig. 7. As argued by Vlasov and Warnatz [67], the experimentally observed bell-shaped curve of soot yield as a function of temperature is caused by PAH kinetics. While the reversible PAH model and the model of Vlasov and Warnatz [67] accurately describe this effect at all carbon atom concentrations, the PAH model from Blacha et al. [35] predicts a monotonically increasing soot yield with increasing temperature. This is because reversibility of PAH chemistry and PAH radicals are neglected. As can be seen from Fig. 7, this erroneous behavior becomes evident at temperatures higher than $2000 \mathrm{~K}$ only. However, accurate soot predictions at such high temperatures are very relevant since technical combustion devices are in many cases operated with preheated air leading to high combustion temperatures. A scaling of the rate coefficient of soot surface growth via $\mathrm{C}_{2} \mathrm{H}_{2}$ addition by a factor of two (dotted line) additionally improves the quantitative agreement to measurements in the 4.0 and $4.7 \mathrm{~mol} / \mathrm{m}^{3}$ cases. In this way, results from the newly proposed model are similar to those obtained by the more detailed and computationally significantly more expensive model of Vlasov and Warnatz [67]. However by using this scaled rate coefficient, the soot yield is overpredicted in the temperature range $1900 \mathrm{~K}<\mathrm{T}<2400 \mathrm{~K}$ for the $7.4 \mathrm{~mol} / \mathrm{m}^{3}$ case. 


\subsection{Prediction of Particle Size Distributions}

Manzello et al. 69] studied PAH growth and soot inception by measurements of soot particle size distributions (PSD) at atmospheric pressure in a device where an ethylene fuelled well-stirred reactor (WSR) is followed by a plug flow reactor (PFR). The soot particle measurements were conducted at the bottom most sampling port of the PFR using a dilution probe followed by a nano-differential mobility analyzer. This measurement technique captures particles with diameters from $3 \mathrm{~nm}$ to $60 \mathrm{~nm}$ using 30 sampling bins. In addition, gas chromatography measurements of selected species are available. The air flow rate was kept constant while the ethylene flow rate was varied to obtain the equivalence ratios $\phi=1.8,1.9,2.0,2.1$, and 2.2. The expanded measurement uncertainty in the reported equivalence ratios is $\pm 3 \%$. The temperature in the PFR was approximately 1400 $\mathrm{K}$ at all equivalence ratios. A major uncertainty is the definition of temperatures in the WSR since temperature measurements are reported only for $\phi=2.0(\mathrm{~T}=1723 \mathrm{~K}$ with a measurement uncertainty of $\pm 10 \%$ ). In the present work the estimated temperatures proposed by Bhatt and Lindstedt [18] are reduced by $5 \%$ (well within the range of measurement uncertainty) to obtain a better agreement with experimental data, resulting in $T=1713 \mathrm{~K}, 1675 \mathrm{~K}, 1637 \mathrm{~K}, 1599 \mathrm{~K}$, and $1561 \mathrm{~K}$ for the $\phi=1.8,1.9,2.0,2.1$, and 2.2 cases. The WSR and PFR are modeled by isobaric, isothermal reactors. Residence times of the WSR and the PFR amount to 11 and 18 ms.

Figure 8 shows a comparison of measured and predicted species mole fractions as a function of the equivalence ratio $\phi$. Calculated acetylene and benzene mole fractions compare well to measurements and the sensitivity with respect to $\phi$ is accurately predicted. Calculated $\mathrm{PAH}_{1}$ mole fractions are compared to measured naphthalene data. Considering the difficulties associated with comparisons of PAH bins and individual PAH species (cf. Fig. 4), a reasonable agreement is observed. Similar as in the study of Bhatt and Lindstedt [18], the naphthalene mole fraction is underpredicted at $\phi$ $=2.2$. Bhatt and Lindstedt [18] attributed this underprediction to the influence of soot nucleation.

Figures 9 and 10 show predicted and measured soot properties. Experimental soot volume fractions $f_{v}$, particle number densities $N$, and mean particle diameters $\bar{d}_{s}$ were obtained by integrating 
the PSD data from Manzello et al. [69] by

$$
\begin{aligned}
& \bar{d}_{s}=\frac{1}{N} \int d_{s} \mathrm{~d} N \\
& f_{v}=\frac{\pi}{6} \int d_{s}^{3} \mathrm{~d} N .
\end{aligned}
$$

Since in the measurements no indication of flame generated particles was found at $\phi=1.8$, the sooting limit is in the range $1.8<\phi<1.9$. The measured soot properties shown in Fig. 10 are monotonically increasing with $\phi$ and the corresponding PSD functions in Fig. 9 are shifted to larger particle diameters and number densities when $\phi$ is increased. At $\phi=2.0$, a local minimum in the measured PSD function indicates bimodality and thus the existence of a nucleation mode. Singh et al. [70] explained bimodal soot PSDs by competing nucleation and coagulation processes. Possible reasons why bimodality is not observed at other equivalence ratios may be the detection limit of the measurement technique (only particles with $d_{s} \geq 3 \mathrm{~nm}$ are detected) and, as argued by Manzello et al. [69], the different mixing properties of a WSR/PFR relative to laminar premixed flames. For the latter ones, Abid et al. [42] found that PSD functions are in general bimodal.

While the model with irreversible PAH chemistry [35] predicts bimodal PSD functions at all equivalence ratios, Bhatt and Lindstedt [18] report unimodal distributions at all equivalence ratios. They used a sectional approach for soot where inception is modeled by pyrene dimerization; combustion and PAH chemistry were described by a detailed mechanism (285 species and 1520 reactions). The model developed in the present work on the other hand shows a transition from unimodal distributions close to the sooting limit to bimodal distributions in the well-sooting regime. The model with irreversible PAH chemistry [35] shows good agreement to measured PSD functions at $\phi=2.0$ and 2.1. This model however overpredicts the PSD function at $\phi=1.8$ by four orders of magnitude and thus fails to predict PSD functions close to the sooting limit. The model with reversible PAH chemistry on the other hand provides excellent predictions of the sooting limit. The shift of the PSD functions to larger particle diameters and number densities with increasing $\phi$ is also in good agreement to the experimental data.

A dominant impact parameter on soot PSD functions is the efficiency of PAH condensation onto soot particles $\gamma_{\text {cond }}$. As shown in table 5, increasing $\gamma_{\text {cond }}$ from the standard value 0.3 to 1.0 
decreases the ratio of nucleation to condensation $\left(\omega_{\text {nucl }} / \omega_{\text {cond }}\right)$ by factors between 3 and 6.75 , since more PAH mass is transferred to soot via the condensation pathway. As shown in Fig. 9, a higher

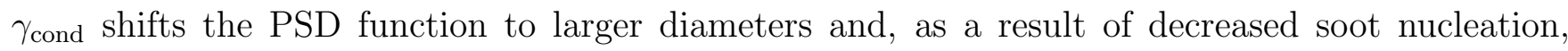
less small particles are observed. A similar effect was observed in modelling studies by Saggese et al. 25] and Veshkini et al [27]. This influence of $\gamma_{\text {cond }}$ on the PSD function is most pronounced in the well sooting regime, for example at $\phi=2.1$, where the PSD function is decreased by two orders of magnitude at particle diameters within the nucleation mode. Similar to a study on reversible nucleation and condensation by Eaves at al. [26], an increase in $\gamma_{\text {cond }}$ yields higher mean particle diameters while the particle number densities are slightly decreased (see Fig. 10). Thus, less particles with larger diameters are predicted. While $\gamma_{\text {cond }}=1.0$ underpredicts the PSD function at small diameters at $\phi=2.1$ and yields too large mean particle diameters, $\gamma_{\text {cond }}=0.3$ achieves a good agreement to measurements at all equivalence ratios.

The excellent agreement of the reversible PAH model to measured mean particle diameters, particle number densities, and soot volume fractions shown in Fig. 10 demonstrates that the soot morphology is accurately described at these challenging combustion conditions, where $N$ and $f_{v}$ increase by several orders of magnitude when $\phi$ is changed from 1.8 to 2.1. With irreversible PAH chemistry, on the other hand, the particle number density is overpredicted and the sensitivity of the soot morphology with respect to $\phi$ is not resolved. Consistent to the laminar flame simulations discussed in section 3.1 , the source term analysis shown in table 5 reveals that in case of irreversible PAH chemistry, the percentage of soot nucleation to the total soot formation rate is, with more than $10 \%$, significantly too high [63, 64, 65]. Realistic values are in the order of 0.1 to $1 \%$ as obtained by the reversible PAH model. Nevertheless, as observed in previous works [34, 35], irreversible PAH chemistry can yield accurate soot volume fraction predictions in the well sooting regime $(\phi>2$ in the present test case). However, resulting from too strong soot nucleation, the soot morphology is not described accurately since compared to measurements, too much particles with too small diameters are observed. As shown in Fig. 11, it was not possible to improve the prediction of particle number densities by slowing down the PAH growth rates of the irreversible model. This indicates that PAH radicals and reversible PAH chemistry are required for accurate predictions of the soot morphology. 


\section{Conclusions}

A new sectional PAH model which uses PAH radicals and reversible PAH chemistry was presented. The new model is validated for a series of combustion configurations, which feature technical relevant aspects such as elevated pressure, high temperature, and partial premixing at equivalence ratios in the range of the sooting limit. In comparison to an irreversible PAH model [35], significant improvements are demonstrated at basically no increase in computational cost. This is important because the aim of these developments are complex CFD soot simulations. The quality of the soot predictions is comparable to more detailed models from the literature.

A changed PAH size distribution is obtained leading to significantly smaller soot nucleation source terms than in case of irreversible PAH chemistry. By the described model developments, the agreement to measured soot volume fractions was improved in a series of laminar premixed flames. The extended description of PAH chemistry allowed to predict the bell-shaped curve of soot yield as a function of temperature. This is of high relevance for soot predictions in technical devices which are in many cases operated at high temperatures. The new model also predicts particle size distributions and their sensitivity with respect to the equivalence ratio accurately. Both is highly challenging especially close to the sooting limit. Moreover, it was found that PAH radicals and a

reversible PAH chemistry are required to accurately predict the soot morphology since irreversible PAH chemistry leads to too strong soot nucleation which results in an overprediction of particle number densities.

\section{Acknowledgements}

The authors thank Dr. K. P. Geigle and A. Steinbach for their contribution to this work. The authors gratefully acknowledge the Gauss Centre for Supercomputing e.V. (www.gauss-centre.eu) for funding this project by providing computing time on the GCS Supercomputer SuperMUC at Leibniz Supercomputing Centre (LRZ, www.lrz.de) 


\section{References}

[1] B. Kärcher (ed.), Particles and cirrus clouds, Tech. rep., German Aerospace Center, http://www.pa.op.dlr.de/pazi/DLR-Mitteilung_2008-01.pdf, accessed at December 2nd, 2015 (2008).

[2] E. J. Jensen, O. B. Toon, The potential impact of soot particles from aircraft exhaust on cirrus clouds, Geophysical Research Letters 24 (1997) 249-252.

[3] A. Petzold, J. Ström, S. Ohlsson, F. P. Schröder, Elemental composition and morphology of ice-crystal residual particles in cirrus clouds and contrails, Atmospheric Research 49 (1998) $21-34$.

[4] A. Petzold, J. Ström, F. P. Schröder, B. Kärcher, Carbonaceous aerosol in jet engine exhaust: emission characteristics and implications for heterogeneous chemical reactions, Atmospheric Environment 33 (1999) 2689-2698.

[5] M. Nakamura, S. Koda, K. Akita, Sooting behavior and radiation in methanol/benzene/air diffusion flames, Proceedings of the Combustion Institute 19 (1982) 1395-1401.

[6] C. Eberle, P. Gerlinger, K. P. Geigle, M. Aigner, Numerical investigation of transient soot evolution processes in an aero-engine model combustor, Combustion Science and Technology 187 (2015) 1841-1866.

[7] K. M. Leung, R. P. Lindstedt, A simplified reaction mechanism for soot formation in nonpremixed flames, Combustion and Flame 87 (1991) 289-305.

[8] A. Kronenburg, R. W. Bilger, J. H. Kent, Modeling soot formation in turbulent methane air jet diffusion flames, Combustion and Flame 121 (2000) 24-40.

[9] R. S. Mehta, D. C. Haworth, M. F. Modest, Composition PDF/photon monte carlo modeling of moderately sooting turbulent jet flames, Combustion and Flame 157 (2010) 982-994. 
[10] G. Lecocq, D. Poitou, I. Hernández, F. Duchaine, E. Riber, B. Cuenot, A methodology for soot prediciton including thermal radiation in complex industrial burners, Flow, Turbulence and Combustion 92 (2014) 947-970.

[11] M. Bolla, D. Farrace, Y. M. Wright, K. Boulouchos, Modelling of soot formation in a heavyduty diesel engine with conditional moment closure, Fuel 117 (2014) 309-325.

[12] S. P. Roy, D. C. Haworth, A systematic comparison of detailed soot models and gas-phase chemical mechanisms in laminar premixed flames, Combustion Science and Technology 188 (2016) 1021-1053.

[13] J. T. McKinnon, J. B. Howard, The roles of PAH and acetylene in soot nucleation and growth, Proceedings of the Combustion Institute 24 (1992) 965-971.

[14] J. D. Bittner, J. B. Howard, Composition profiles and reaction mechanisms in a near-sooting premixed benzene/oxygen/argon flame, Proceedings of the Combustion Institute 18 (1981) 1105-1116.

[15] M. Bachmann, W. Wiese, K. H. Homann, PAH and aromers: Precursors of fullerenes and soot, Proceedings of the Combustion Institute 26 (1996) 2259-2267.

[16] W. J. Grieco, A. L. Lafleur, K. C. Swallow, H. Richter, K. Taghizadeh, J. B. Howard, Fullerenes and PAH in low-pressure premixed benzene/oxygen flames, Proceedings of the Combustion Institute 27 (1998) 1669-1675.

[17] A. Ciajolo, R. Barbella, A. Tregrossi, L. Bonfanti, Spectroscopic and compositional signatures of PAH-loaded mixtures in the soot inception region of a premixed ethylene flame, Proceedings of the Combustion Institute 27 (1998) 1481-1487.

[18] J. S. Bhatt, R. P. Lindstedt, Analysis of the impact of agglomeration and surface chemistry models on soot formation and oxidation, Proceedings of the Combustion Institute 32 (2009) 713-720. 
[19] S. B. Dworkin, Q. Zhang, M. J. Thomson, N. A. Slavinskaya, U. Riedel, Application of an enhanced PAH growth model to soot formation in a laminar coflow ethylene/air diffusion flame, Combustion and Flame 158 (2011) 1682-1695.

[20] N. A. Slavinskaya, P. Frank, A modelling study of aromatic soot precursors formation in laminar methane and ethene flames, Combustion and Flame 156 (2009) 1705-1722.

[21] M. R. Kholghy, A. Veshkini, M. J. Thomson, The core-shell internal nanostructure of soot - a criterion to model soot maturity, Carbon 100 (2016) 508-536.

[22] H. Richter, S. Granata, W. H. Green, J. B. Howard, Detailed modeling of PAH and soot formation in a laminar premixed benzene/oxygen/argon low-pressure flame, Proceedings of the Combustion Institute 30 (2005) 1397-1405.

[23] M. Frenklach, H. Wang, Detailed modeling of soot particle nucleation and growth, Proceedings of the Combustion Institute 23 (1990) 1559-1556.

[24] A. D’Anna, M. Sirignano, J. Kent, A model of particle nucleation in premixed ethylene flames, Combustion and Flame 157 (2010) 2106-2115.

[25] C. Saggese, S. Ferrario, J. Camacho, A. Cuoci, A. Frassoldati, E. Ranzi, H. Wang, T. Faravelli, Kinetic modeling of particle size distribution of soot in a premixed burner-stabilized stagnation ethylene flame, Combustion and Flame 162 (2015) 3356-3369.

[26] N. A. Eaves, S. B. Dworkin, M. J. Thomson, The importance of reversibility in modeling soot nucleation and condensation processes, Proceedings of the Combustion Institute 35 (2015) $1787-1794$.

[27] A. Veshkini, N. A. Eaves, M. J. Thomson, Application of PAH-condensation reversibility in modeling soot growth in laminar premixed and nonpremixed flames, Combustion and Flame 167 (2016) 335-352.

[28] H. Pitsch, E. Riesmeier, N. Peters, Unsteady flamelet modeling of soot formation in turbulent diffusion flames, Combustion Science and Technology 158 (2000) 389-406. 
[29] M. E. Mueller, H. Pitsch, LES model for sooting turbulent nonpremixed flames, Combustion and Flame 159 (2012) 2166-2180.

[30] C. D. Pierce, P. Moin, Progress-variable approach for large-eddy simulation of non-premixed combustion, Journal of Fluid Mechanics 504 (2004) 73-97.

[31] F. Bisetti, G. Blanquart, M. Mueller, H. Pitsch, On the formation and early evolution of soot in turbulent nonpremixed flames, Combustion and Flame 159 (2012) 317-335.

[32] Y. Xuan, G. Blanquart, A flamelet-based a priori analysis of the chemistry tabulation of polycyclic aromatic hydrocarbons in non-premixed flames, Combustion and Flame 161 (2014) $1516-1525$.

[33] B. Zamuner, F. Dupoirieux, Numerical simulation of soot formation in a turbulent flame with a Monte-Carlo PDF approach and detailed chemistry, Combustion Science and Technology 158 (2000) 407-438.

[34] M. Di Domenico, P. Gerlinger, M. Aigner, Development and validation of a new soot formation model for gas turbine combustor simulations, Combustion and Flame 157 (2010) 246-258.

[35] T. Blacha, M. Di Domenico, P. Gerlinger, M. Aigner, Soot predictions in premixed and nonpremixed laminar flames using a sectional approach for PAHs and soot, Combustion and Flame 159 (2012) 181-193.

[36] M. Köhler, K. P. Geigle, T. Blacha, P. Gerlinger, W. Meier, Experimental characterization and numerical simulation of a sooting lifted turbulent jet diffusion flame, Combustion and Flame 159 (2012) 2620-2635.

[37] K. P. Geigle, M. Köhler, W. O’Loughlin, W. Meier, Investigation of soot formation in pressurized swirl flames by laser measurements of temperature, flame structures and soot concentrations, Proceedings of the Combustion Institute 35 (2015) 3373-3380.

[38] F. A. Williams, Combustion Theory, Addison-Wesley, 1997. 
[39] M. Di Domenico, Numerical simulations of soot formation in turbulent flows, Ph.D. thesis, Institute of Combustion Technology for Aerospace Engineering Universität Stuttgart (2008).

[40] Friedlander, Smoke, dust and haze: Fundamentals of aerosol behavior, Wiley-Interscience, 1977.

[41] N. A. Slavinskaya, O. J. Haidn, Reduced chemical model for high pressure methane combustion with PAH formation, in: Proceedings of the 46th AIAA Aerospace Sciences Meeting, no. AIAA 2008-1012, 2008.

[42] A. D. Abid, E. D. Tolmachiff, D. J. Phares, H. Wang, Y. Liu, A. Laskin, Size distribution and morphology of nascant soot in premixed ethylene flames with and without benzene doping, Proceedings of the Combustion Institute 32 (2009) 681-688.

[43] J. Yu, R. Sumathi, W. Green Jr., Accurate and efficient method for predicting thermochemistry of polycyclic aromatic hydrocarbons - bond-centered group additivity, Journal of the American Chemical Society 126 (2004) 12685-12700.

[44] A. Burcat, Ideal gas thermodynamic data in polynomial form for combustion and air pollution use, http://tx.technion.ac.il/ aer0201/, accessed at December 2nd, 2015.

[45] H. Richter, T. G. Benish, O. A. Mazyar, W. H. Green, J. B. Howard, Formation of polycyclic aromatic hydrocarbons and their radicals in a nearly sooting premixed benzene flame, Proceedings of the Combustion Institute 28 (2000) 2609-2618.

[46] N. A. Slavinskaya, U. Riedel, S. B. Dworkin, M. J. Thomson, Detailed numerical modeling of PAH formation and growth in non-premixed ethylene and ethane flames, Combustion and Flame 159 (2012) 979-995.

[47] M. Frenklach, H. Wang, Detailed mechanism and modeling of soot particle formation, in: H. Bockhorn (Ed.), Soot Formation in Combustion, Springer Verlag, 1994.

[48] C. J. Pope, J. B. Howard, Simultaneous particle and molecule modeling (SPAMM): An approach for combining sectional aerosol equations and elementary gas-phase reactions, Aerosol Science and Technology 27 (1997) 73-94. 
[49] A. Khosousi, S. B. Dworkin, Detailed modelling of soot oxidation by $\mathrm{O}_{2}$ and $\mathrm{OH}$ in laminar diffusion flames, Proceedings of the Combustion Institute 35 (2014) 1903-1910.

[50] N. A. Fuchs, The Mechanics of Aerosols, Pergamon Press, Oxford, 1964.

[51] A. D’Alessio, A. C. Barone, R. Cau, A. D’Anna, P. Minutolo, Surface deposition and coagulation efficiency of combustion generated nanoparticles in the size range from 1 to $10 \mathrm{~nm}$, Proceedings of the Combustion Institute 30 (2005) 2595-2603.

[52] A. D’Anna, J. H. Kent, A model of particulate and species formation applied to laminar, nonpremixed flames for three aliphatic-hydrocarbon fuels, Combustion and Flame 152 (2008) 573-587.

[53] F. Gelbard, J. H. Seinfeld, Simulation of multicomponent aerosol dynamics, Journal of Colloid and Interface Science 78 (1980) 485-501.

[54] M. S. Tsurikov, K. P. Geigle, V. Krüger, Y. Schneider-Kühnle, W. Stricker, R. Lückerath, R. Hadef, M. Aigner, Laser-based investigation of soot formation in laminar premixed flames at atmospheric and elevated pressures, Combustion Science and Technology 177 (2005) 18351862.

[55] M. J. Castaldi, N. M. Marinov, C. F. Mellius, J. Huang, S. M. Senkan, W. J. Pitz, C. K. Westbrook, Experimental and modeling investigation of aromatic and polycyclic aromatic hydrocarbon formation in a premixed ethylene flame, Proceedings of the Combustion Institute 26 (1996) 693-702.

[56] H. Böhm, M. Braun-Unkhoff, P. Frank, Investigations on initial soot formation at high pressures, Progress in Computational Fluid Dynamics 3 (2003) 145-150.

[57] A. Di Lorenzo, A. D’Alessio, V. Cincotti, S. Masi, P. Menna, C. Venitozzi, UV absorption, laser excited fluorescence and direct sampling in the study of the formation of polycyclic aromatic hydrocarbons in rich $\mathrm{CH}_{4} / \mathrm{O}_{2}$ flames, Proceedings of the Combustion Institute 18 (1980) 485491. 
[58] R. Wang, P. Cadman, Soot and PAH production from spray combustion of different hydrocarbons behind reflected shock waves, Combustion and Flame 112 (1998) 359-370.

[59] N. E. Sánchez, A. Callejas, A. Millera, R. Bilbao, M. U. Alzueta, Polycyclic aromatic hydrocarbon $(\mathrm{PAH})$ and soot formation in the pyrolysis of acetylene and ethylene: effect of the reaction temperature, Energy \& Fuels 26 (2012) 4823-4829.

[60] N. E. Sánchez, A. Callejas, A. Millera, R. Bilbao, M. U. Alzueta, Formation of PAH and soot during acetylene pyrolysis at different gas residence, Energy 43 (2012) 30-36.

[61] T. G. Benish, PAH radical scavenging in fuel-rich premixed benzene flames, Ph.D. thesis, Massachusetts Institute of Technology (1999).

[62] J. Griesheimer, K. H. Homann, Large-molecules, radicals, ions, and small soot particles in fuel-rich hydrocarbon flames, Proceedings of the Combustion Institute 27 (1998) 1753-1759.

[63] F. Xu, P. B. Sunderland, G. M. Faeth, Soot formation in laminar premixed ethylene/air flames at atmospheric pressure, Combustion and Flame 108 (1997) 471-493.

[64] A. Kazakov, H. Wang, M. Frenklach, Detailed modeling of soot formation in laminar premixed ethylene flames at a pressure of 10 bar, Combustion and Flame 100 (1995) 111-120.

[65] M. Balthasar, M. Frenklach, Detailed kinetic modeling of soot aggregate formation in laminar premixed flames, Combustion and Flame 140 (2005) 130-145.

[66] N. A. Eaves, A. Veshkini, C. Riese, Q. Zhang, S. B. Dworkin, M. J. Thomson, A numerical study of high pressure, laminar, sooting, ethane-air coflow diffusion flames, Combustion and Flame 159 (2012) 3179-3190.

[67] P. A. Vlasov, J. Warnatz, Detailed kinetic modeling of soot formation in hydrocarbon pyrolysis behind shock waves, Proceedings of the Combustion Institute 29 (2002) 2335-2341.

[68] P. Deuflhard, M. Wulkow, Computational treatment of polyreaction kinetics by orthogonal polynomials of a discrete variable, IMPACT of Computing in Science and Engineering 1 (1989) $269-301$. 
[69] S. L. Manzello, D. B. Lenhert, A. Yozgatligil, M. T. Donovan, G. W. Mulholland, M. R. Zachariah, W. Tsang, Soot particle size distributions in a well stirred reactor/ plug flow reactor, Proceedings of the Combustion Institute 31 (2007) 675-683.

[70] J. Singh, R. I. A. Patterson, M. Kraft, H. Wang, Numerical simulation and sensitivity analysis of detailed soot particle size distribution in laminar premixed ethylene flames, Combustion and Flame 145 (2006) 117-127. 
Table 1: Summary of PAH chemistry, collisions, and condensation. Reaction rates are in Arrhenius form: $k=k_{0} T^{\alpha} \exp \left(-T / T_{a}\right)$. Units are mol, $\mathrm{cm}, \mathrm{s}$, and $\mathrm{K}$.

\begin{tabular}{|c|c|c|c|c|}
\hline \multicolumn{2}{|c|}{$P A H_{1}$ gas phase interaction } & \multirow{2}{*}{$\frac{k_{0}}{2.5 \mathrm{E}+12}$} & \multirow{2}{*}{$\begin{array}{r}\alpha \\
0.0\end{array}$} & \multirow{2}{*}{$\begin{array}{r}T_{a} \\
3095\end{array}$} \\
\hline $\mathrm{A} 1^{*}+\mathrm{C}_{2} \mathrm{H}_{4}$ & $=\quad \nu \mathrm{PAH}_{1}+\mathrm{H}$ & & & \\
\hline $\mathrm{A} 1^{*}+\mathrm{C}_{3} \mathrm{H}_{4}$ & $=\quad \nu \mathrm{PAH}_{1}+\mathrm{H}$ & $1.0 \mathrm{E}+16$ & 0.0 & 16600 \\
\hline $\mathrm{A}^{*}+\mathrm{H}_{2} \mathrm{CCCH}$ & $=\quad \nu \mathrm{PAH}_{1}$ & $6.5 \mathrm{E}+12$ & 0.0 & 0 \\
\hline $\mathrm{A} 1^{*}+\mathrm{C}_{4} \mathrm{H}_{2}$ & $=\nu \mathrm{PAH}_{1}+\mathrm{C}_{2} \mathrm{H}$ & $2.0 \mathrm{E}+11$ & 0.0 & 0 \\
\hline $\mathrm{A} 1+\mathrm{C}_{2} \mathrm{H}$ & $=\nu \mathrm{PAH}_{1}+\mathrm{H}$ & $1.0 \mathrm{E}+12$ & 0.0 & 0 \\
\hline $\mathrm{A} 1+\mathrm{C}_{2} \mathrm{H}_{3}$ & $=\nu \mathrm{PAH}_{1}+\mathrm{H}$ & $7.9 \mathrm{E}+11$ & 0.0 & 3200 \\
\hline $\mathrm{A} 1+\mathrm{A} 1^{*}$ & $=\quad \nu \mathrm{PAH}_{1}+\mathrm{H}$ & $1.1 \mathrm{E}+23$ & -2.9 & 7450 \\
\hline $\mathrm{A} 1^{*}+\mathrm{A} 1^{*}$ & $=\quad \nu \mathrm{PAH}_{1}$ & $2.0 \mathrm{E}+26$ & -3.9 & 3180 \\
\hline $\mathrm{C}_{7} \mathrm{H}_{7}+\mathrm{CH}_{2}$ & $=\quad \nu \mathrm{PAH}_{1}+\mathrm{H}$ & $2.4 \mathrm{E}+14$ & 0.0 & 0 \\
\hline $\mathrm{C}_{7} \mathrm{H}_{7}+\mathrm{H}_{2} \mathrm{CCCH}$ & $=\nu \mathrm{PAH}_{1}+2 \mathrm{H}$ & $3.0 \mathrm{E}+12$ & 0.0 & 0 \\
\hline $\mathrm{C}_{7} \mathrm{H}_{7}+\mathrm{C}_{2} \mathrm{H}_{2}$ & $=\quad \nu \mathrm{PAH}_{1}+\mathrm{H}$ & $3.2 \mathrm{E}+11$ & 0.0 & 3522 \\
\hline$\nu \mathrm{PAH}_{1}+\mathrm{H}$ & $=\mathrm{A} 1^{*}+\mathrm{C}_{2} \mathrm{H}_{2}$ & $2.0 \mathrm{E}+14$ & 0.0 & 4882 \\
\hline$\nu \mathrm{PAH}_{1}+\mathrm{O}$ & $=\mathrm{A} 1^{*}+\mathrm{HCCO}$ & $2.1 \mathrm{E}+07$ & 2.0 & 950 \\
\hline$\nu \mathrm{PAH}_{1}+\mathrm{O}$ & $=\mathrm{A} 1^{*}+\mathrm{CH}_{3}+\mathrm{CO}$ & $1.9 \mathrm{E}+07$ & 1.8 & 110 \\
\hline$\nu \mathrm{PAH}_{1}+\mathrm{O}$ & $=\mathrm{C}_{7} \mathrm{H}_{7}+\mathrm{HCCO}$ & $2.0 \mathrm{E}+13$ & 0.0 & 2000 \\
\hline$\nu \mathrm{PAH}_{1}+\mathrm{OH}$ & $=\mathrm{A} 1^{*}+\mathrm{CH}_{2} \mathrm{CO}$ & $2.2 \mathrm{E}-04$ & 4.5 & -500 \\
\hline$\nu \mathrm{PAH}_{1}+\mathrm{OH}$ & $=\mathrm{A} 1+\mathrm{HCCO}$ & $2.4 \mathrm{E}+03$ & 3.0 & 5574 \\
\hline$\nu \mathrm{PAH}_{1}+\mathrm{OH}$ & $=\mathrm{C}_{7} \mathrm{H}_{7}+\mathrm{CH}_{2} \mathrm{O}$ & $1.4 \mathrm{E}+12$ & 0.0 & 0 \\
\hline$\nu \mathrm{PAH}_{1}+\mathrm{OH}$ & $=\mathrm{C}_{7} \mathrm{H}_{7}+\mathrm{CH}_{2} \mathrm{CO}$ & $1.0 \mathrm{E}+13$ & 0.0 & 5000 \\
\hline $\mathrm{H}_{2} \mathrm{CCCCH}+\mathrm{C}_{4} \mathrm{H}_{2}$ & $=\nu \mathrm{PAH}_{1}^{*}$ & $9.6 \mathrm{E}+70$ & -17.8 & 15660 \\
\hline $\mathrm{C}_{5} \mathrm{H}_{5}+\mathrm{H}_{2} \mathrm{CCCH}$ & $=\nu \mathrm{PAH}_{1}^{*}+\mathrm{H}$ & $3.0 \mathrm{E}+35$ & -7.2 & 4234 \\
\hline $\mathrm{A}^{*}+\mathrm{H}_{2} \mathrm{CCCH}$ & $=\quad \nu \mathrm{PAH}_{1}^{*}+\mathrm{H}$ & $2.0 \mathrm{E}-10$ & 7.1 & 786 \\
\hline $\mathrm{C}_{5} \mathrm{H}_{5}+\mathrm{C}_{4} \mathrm{H}_{2}$ & $=\nu \mathrm{PAH}_{1}^{*}$ & $1.2 \mathrm{E}+12$ & 0.0 & 5030 \\
\hline$\nu \mathrm{PAH}_{1}^{*}$ & $\rightarrow \mathrm{C}_{2} \mathrm{H}_{2}+\mathrm{C}_{4} \mathrm{H}_{2}+\mathrm{H}_{2} \mathrm{CCCH}$ & $1.0 \mathrm{E}+14$ & 0.0 & 37500 \\
\hline $2 \mathrm{~A} 1^{*}$ & $=\nu \mathrm{PAH}_{1}^{*}+\mathrm{H}$ & $2.3 \mathrm{E}-01$ & 4.6 & 14500 \\
\hline \multicolumn{2}{|c|}{ PAH dehydrogenation $(1 \leq i \leq 3)$} & $k_{0}$ & $\alpha$ & $T_{a}$ \\
\hline $\mathrm{PAH}_{i}+\mathrm{OH}$ & $=\mathrm{PAH}_{i}^{*}+\mathrm{H}_{2} \mathrm{O}$ & $2.1 \mathrm{E}+13$ & 0.0 & 2300 \\
\hline $\mathrm{PAH}_{i}+\mathrm{H}$ & $=\mathrm{PAH}_{i}^{*}+\mathrm{H}_{2}$ & $2.5 \mathrm{E}+14$ & 0.0 & 8000 \\
\hline $\mathrm{PAH}_{i}+\mathrm{O}$ & $=\mathrm{PAH}_{i}^{*}+\mathrm{OH}$ & $2.0 \mathrm{E}+13$ & 0.0 & 7400 \\
\hline $\mathrm{PAH}_{i}^{*}+\mathrm{H}$ & $=\mathrm{PAH}_{i}$ & $1.0 \mathrm{E}+14$ & 0.0 & 0 \\
\hline \multicolumn{2}{|c|}{$P A H$ growth $(1 \leq i \leq 3)$} & $k_{0}$ & $\alpha$ & $T_{a}$ \\
\hline $\mathrm{PAH}_{i}^{*}+\mathrm{C}_{2} \mathrm{H}_{2}$ & $\rightarrow \quad \nu_{1} \mathrm{PAH}_{i}+\nu_{2} \mathrm{PAH}_{i+1}+\nu_{3} \mathrm{H}$ & $1.2 \mathrm{E}+26$ & -3.4 & 15100 \\
\hline $\mathrm{H}+\mathrm{PAH}_{i}$ & $\rightarrow \quad \nu_{1} \mathrm{PAH}_{i-1}^{*}+\nu_{2} \mathrm{PAH}_{i}^{*}+\nu_{3} \mathrm{H}_{2}+\mathrm{C}_{2} \mathrm{H}_{2}$ & $3.6 \mathrm{E}+30$ & -4.3 & 19672 \\
\hline \multicolumn{2}{|c|}{ PAH oxidation $(1 \leq i \leq 3)$} & $k_{0}$ & $\alpha$ & $T_{a}$ \\
\hline $\mathrm{PAH}_{i}+\mathrm{O}$ & $\rightarrow \quad \nu_{1} \mathrm{PAH}_{i-1}^{*}+\nu_{2} \mathrm{PAH}_{i}^{*}+\nu_{3} \mathrm{H}_{2}+\mathrm{HCCO}$ & $2.0 \mathrm{E}+13$ & 0.0 & 2100 \\
\hline $\mathrm{PAH}_{i}^{*}+\mathrm{O}$ & $\rightarrow \quad \nu_{1} \mathrm{PAH}_{i-1}^{*}+\nu_{2} \mathrm{PAH}_{i}^{*}+\nu_{3} \mathrm{H}_{2}+\mathrm{CO}$ & $1.0 \mathrm{E}+14$ & 0.0 & 0 \\
\hline $\mathrm{PAH}_{i}+\mathrm{OH}$ & $\rightarrow \nu_{1} \mathrm{PAH}_{i-1}^{*}+\nu_{2} \mathrm{PAH}_{i}^{*}+\nu_{3} \mathrm{H}_{2}+\mathrm{CH}_{2} \mathrm{CO}$ & $1.3 \mathrm{E}+13$ & 0.0 & 5300 \\
\hline $\mathrm{PAH}_{i}^{*}+\mathrm{O}_{2}$ & $\rightarrow \quad \nu_{1} \mathrm{PAH}_{i-1}^{*}+\nu_{2} \mathrm{PAH}_{i}^{*}+\nu_{3} \mathrm{H}_{2}+2 \mathrm{CO}$ & $2.0 \mathrm{E}+12$ & 0.0 & 3700 \\
\hline \multicolumn{5}{|c|}{ PAH collisions $(i, j \in[1,3]$ and $k=\max (i, j))$} \\
\hline $\mathrm{PAH}_{i}^{*}+\mathrm{PAH}_{j}^{*}$ & $\rightarrow \quad \nu_{1} \mathrm{PAH}_{k}+\nu_{2} \mathrm{PAH}_{k+1}+\nu_{3} \mathrm{H}_{2}$ & \multicolumn{3}{|c|}{ see section 2.2 .3} \\
\hline $\mathrm{PAH}_{i}^{*}+\mathrm{PAH}_{j}$ & $\rightarrow \quad \nu_{1} \mathrm{PAH}_{k}+\nu_{2} \mathrm{PAH}_{k+1}+\nu_{3} \mathrm{H}_{2}+\mathrm{H}$ & \multicolumn{3}{|c|}{ see section 2.2 .3} \\
\hline \multicolumn{5}{|c|}{ PAH condensation onto soot particles $(1 \leq i \leq 3$ and $1 \leq j \leq 24)$} \\
\hline $\mathrm{PAH}_{i}+\mathrm{SOOT}_{j}$ & $\rightarrow \nu_{1} \mathrm{SOOT}_{j}+\nu_{2} \mathrm{SOOT}_{j+1}+\nu_{3} \mathrm{H}_{2}$ & \multirow{2}{*}{\multicolumn{3}{|c|}{$\begin{array}{l}\text { see section } 2.2 .3 \\
\text { see section } \\
2.2 .3\end{array}$}} \\
\hline $\mathrm{PAH}_{i}^{*}+\mathrm{SOOT}_{j}$ & $\rightarrow \quad \nu_{1} \mathrm{SOOT}_{j}+\nu_{2} \mathrm{SOOT}_{j+1}+\nu_{3} \mathrm{H}_{2}+\mathrm{H}$ & & & \\
\hline
\end{tabular}


Table 2: Model comparison. The number of species and reactions includes gas phase species and PAHs.

\begin{tabular}{lcl}
\hline & Number of species/reactions & Soot incipient species \\
\hline present work & $49 / 524$ & $\mathrm{PAH}_{3}, \mathrm{PAH}_{3}^{*}$ \\
Blacha et al. [35] & $46 / 413$ & $\mathrm{PAH}_{3}$ \\
Slavinskaya et al. [20] & $93 / 729$ & all PAHs between pyrene and benzo(a)pyrene \\
Vlasov and Warnatz [67] & $141 / 1700$ & lumped soot precursor species \\
Bhatt and Lindstedt [18] & $285 / 1520$ & pyrene \\
\hline
\end{tabular}

Table 3: Boundary conditions of laminar premixed flames.

\begin{tabular}{ccccc}
\hline Fuel & Pressure $[$ bar $]$ & $\phi$ & $u_{\text {in }}[\mathrm{m} / \mathrm{s}]$ & \multicolumn{1}{c}{ Reference } \\
\hline $\mathrm{C}_{2} \mathrm{H}_{4}$ & 1 & 2.3 & 0.073 & Tsurikov et al. [54] \\
$\mathrm{C}_{2} \mathrm{H}_{4}$ & 1 & 3.06 & 0.059 & Castaldi et al. [55] \\
$\mathrm{C}_{2} \mathrm{H}_{4}$ & 3 & 2.3 & 0.248 & Tsurikov et al. [54] \\
$\mathrm{C}_{2} \mathrm{H}_{4}$ & 3 & 2.5 & 0.250 & Tsurikov et al. [54] \\
\hline
\end{tabular}

Table 4: Soot formation source terms in laminar premixed flames. $\omega_{s}$ is the sum of nucleation, $\mathrm{C}_{2} \mathrm{H}_{2}$ addition, and PAH condensation in $\left[\mathrm{g} /\left(\mathrm{s} \mathrm{m}^{3}\right)\right] . \omega_{\text {nucl }} / \omega_{s}, \omega_{\mathrm{C}_{2} \mathrm{H}_{2} \text {-growth }} / \omega_{s}$, and $\omega_{\text {cond }} / \omega_{s}$ are the percentages of nucleation, $\mathrm{C}_{2} \mathrm{H}_{2}$ addition, and $\mathrm{PAH}$ condensation.

\begin{tabular}{|c|c|c|c|c|c|c|c|c|c|}
\hline \multicolumn{2}{|c|}{ Conditions } & \multicolumn{4}{|c|}{ Irrev. PAH } & \multicolumn{4}{|c|}{ Rev. PAH } \\
\hline $\mathrm{p}$ & $\phi$ & $\omega_{s}$ & $\omega_{\text {nucl }} / \omega_{s}$ & $\omega_{\mathrm{C}_{2} \mathrm{H}_{2} \text {-growth }} / \omega_{s}$ & $\omega_{\text {cond }} / \omega_{s}$ & $\omega_{s}$ & $\omega_{\text {nucl }} / \omega_{s}$ & $\omega_{\mathrm{C}_{2} \mathrm{H}_{2} \text {-growth }} / \omega_{s}$ & $\omega_{\text {cond }} / \omega_{s}$ \\
\hline 1.0 & 2.3 & 27.5 & 24.80 & 63.36 & 11.84 & 5.2 & 0.16 & 81.56 & 18.28 \\
\hline 1.0 & 3.1 & 98.6 & 45.40 & 35.23 & 19.37 & 32.5 & 0.11 & 38.88 & 61.01 \\
\hline 3.0 & 2.3 & 49.7 & 23.95 & 62.79 & 13.26 & 22.9 & 0.18 & 73.81 & 26.01 \\
\hline 3.0 & 2.5 & 86.7 & 25.14 & 59.63 & 15.23 & 53.8 & 0.15 & 69.48 & 30.37 \\
\hline
\end{tabular}

Table 5: Time-integrated soot formation source terms in a WSR/PFR network. $\omega_{s}$ is the sum of nucleation, $\mathrm{C}_{2} \mathrm{H}_{2}$ addition, and $\mathrm{PAH}$ condensation in $\mathrm{kg} / \mathrm{m}^{3} . \omega_{\text {nucl }} / \omega_{s}$ is the percentage of nucleation and $\omega_{\text {nucl }} / \omega_{\text {cond }}$ is the ratio of nucleation to PAH condensation.

\begin{tabular}{c|ccc|ccc|ccc}
\hline & \multicolumn{3}{|c|}{ Irrev. PAH } & \multicolumn{3}{c|}{ Rev. PAH } & \multicolumn{3}{c}{ Rev. PAH, $\gamma_{\text {cond }}=1.0$} \\
$\phi$ & $\omega_{s}$ & $\omega_{\text {nucl }} / \omega_{s}$ & $\omega_{\text {nucl }} / \omega_{\text {cond }}$ & $\omega_{s}$ & $\omega_{\text {nucl }} / \omega_{s}$ & $\omega_{\text {nucl }} / \omega_{\text {cond }}$ & $\omega_{s}$ & $\omega_{\text {nucl }} / \omega_{s}$ & $\omega_{\text {nucl }} / \omega_{\text {cond }}$ \\
\hline 1.8 & $3.2 \mathrm{E}-06$ & 20.0 & 16.8 & $1.4 \mathrm{E}-11$ & 10.5 & 0.48 & $2.5 \mathrm{E}-11$ & 5.9 & 0.12 \\
1.9 & $4.5 \mathrm{E}-06$ & 13.0 & 19.5 & $9.7 \mathrm{E}-08$ & 1.6 & 0.027 & $4.4 \mathrm{E}-07$ & 0.33 & 0.004 \\
2.0 & $6.8 \mathrm{E}-05$ & 13.4 & 5.8 & $3.4 \mathrm{E}-05$ & 0.6 & 0.011 & $4.9 \mathrm{E}-05$ & 0.18 & 0.003 \\
2.1 & $1.2 \mathrm{E}-04$ & 11.7 & 5.2 & $2.0 \mathrm{E}-04$ & 0.5 & 0.009 & $2.6 \mathrm{E}-04$ & 0.11 & 0.002 \\
\hline
\end{tabular}




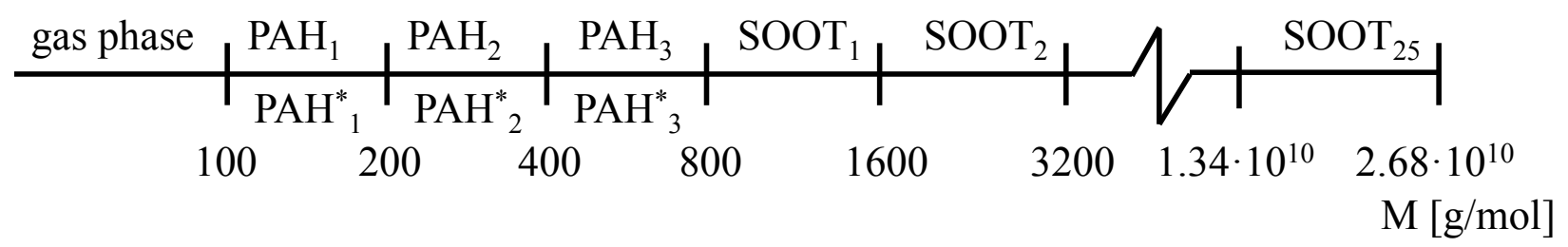

Figure 1: Definition of the PAH, $\mathrm{PAH}^{*}$, and soot sections.

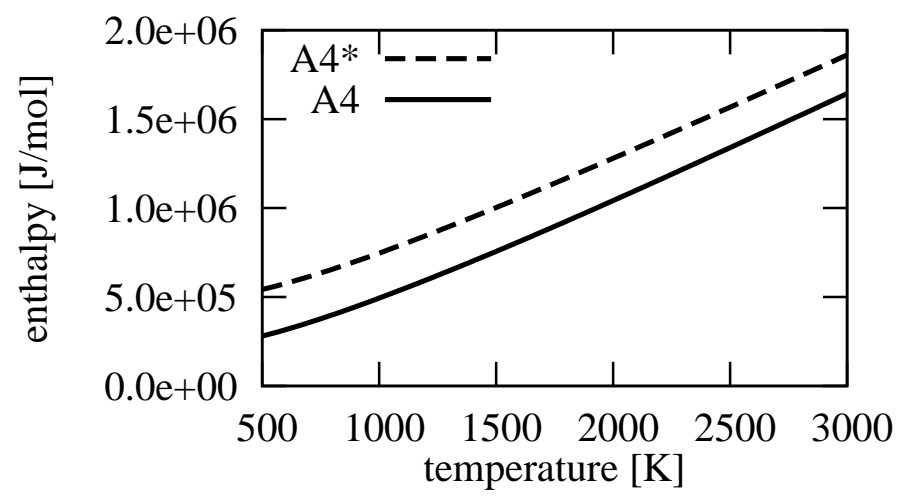

Figure 2: Specific enthalpy of pyrene (A4) and the pyrene radical $\left(\mathrm{A} 4^{*}\right)$.
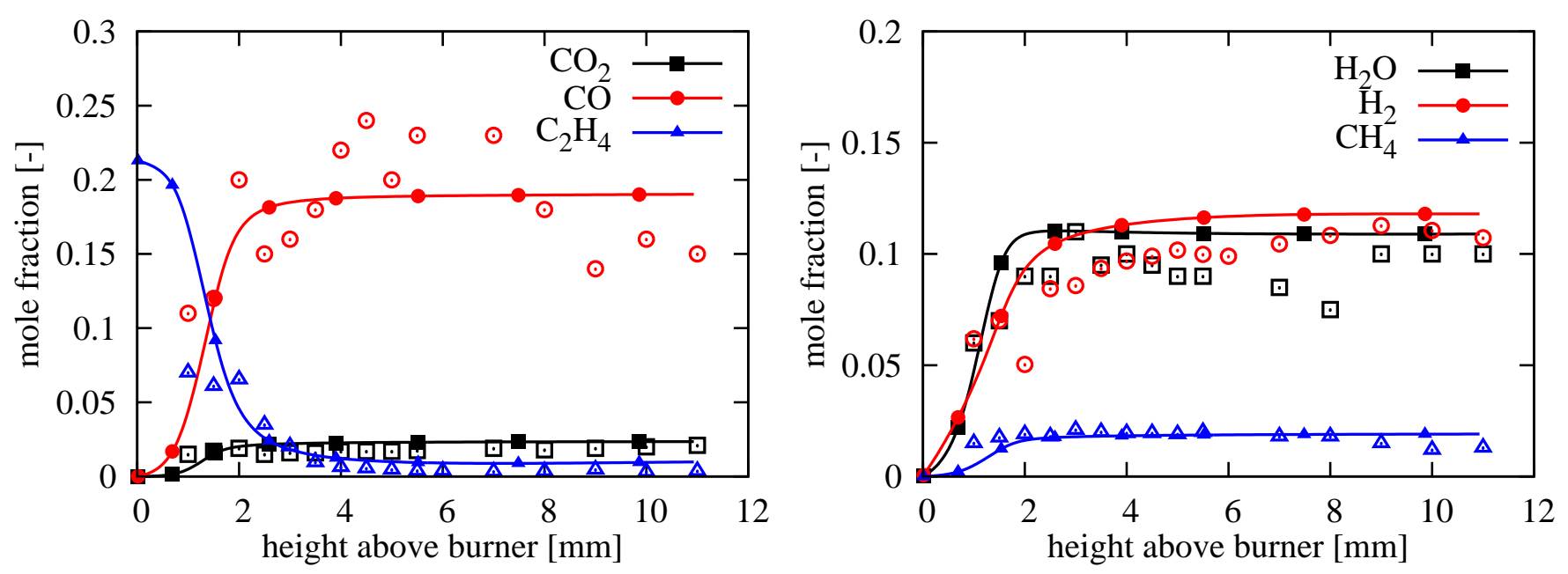

Figure 3: Calculated and measured profiles of selected major species in an atmospheric laminar premixed $\mathrm{C}_{2} \mathrm{H}_{4}$ flame [55]. Open symbols are measurements [55] and lines are simulations using the reversible PAH model. 

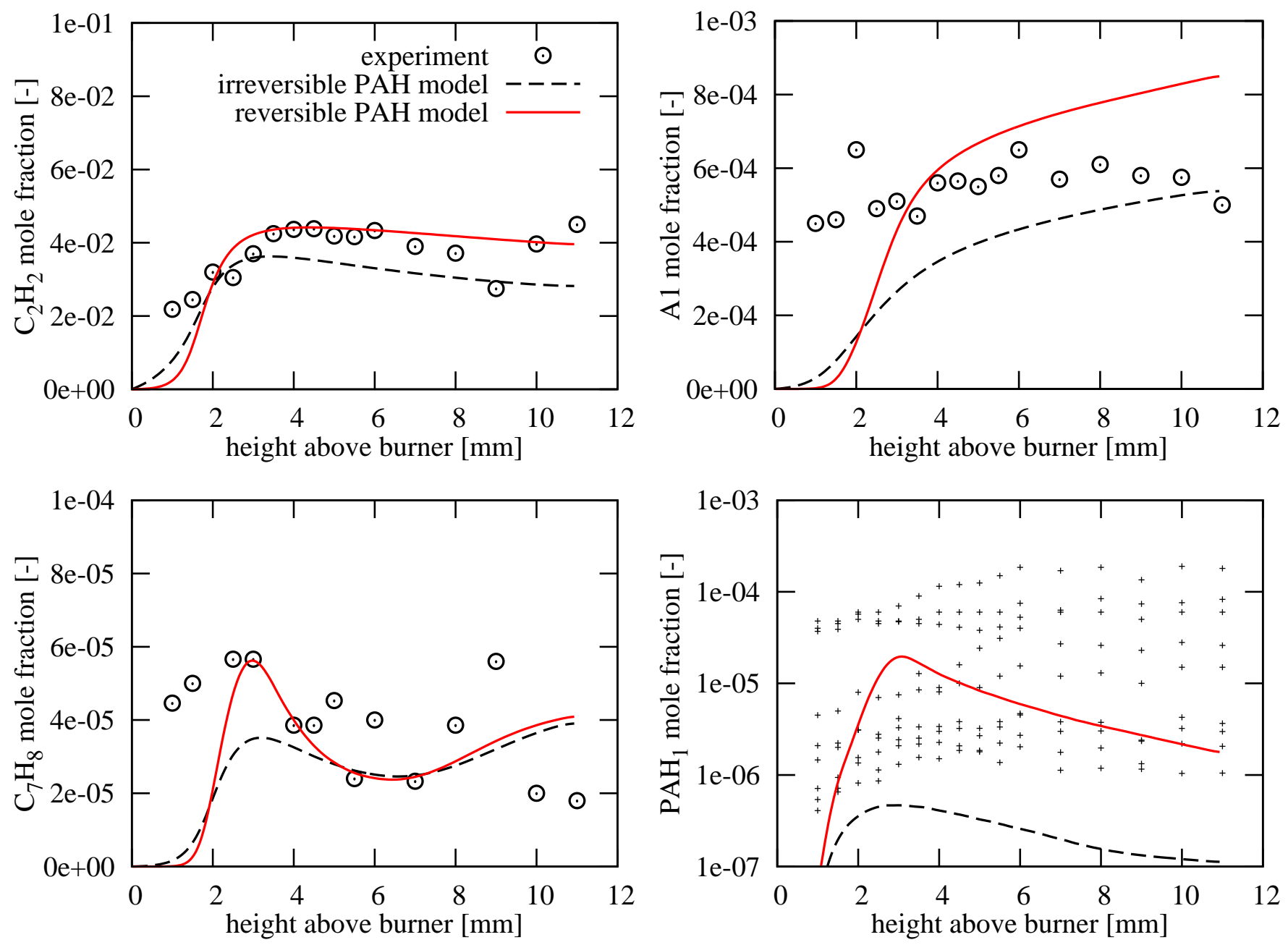

Figure 4: Predicted and measured profiles of species mole fractions in an atmospheric laminar premixed $\mathrm{C}_{2} \mathrm{H}_{4}$ flame [55]. 

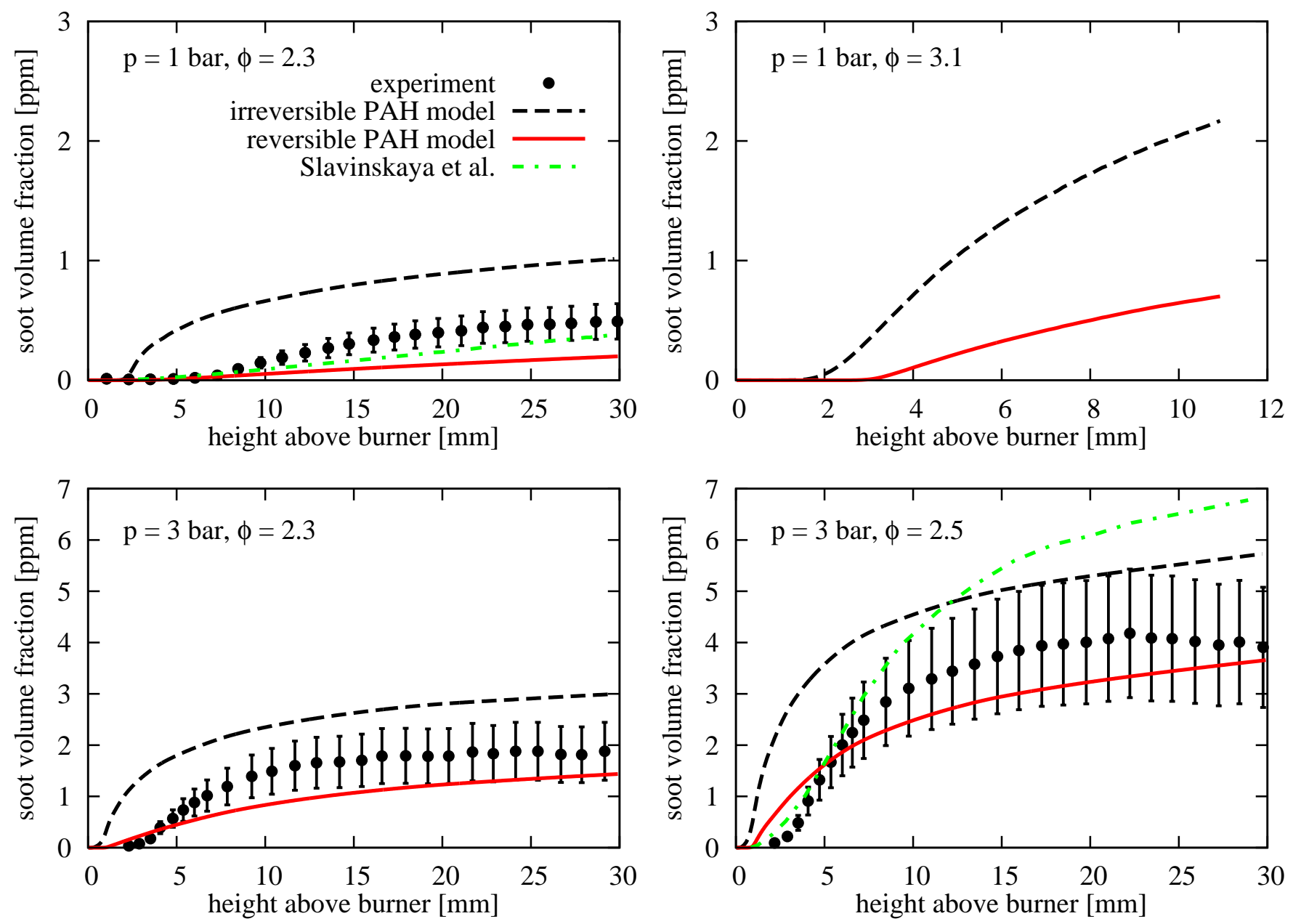

Figure 5: Measured and predicted soot volume fractions in laminar premixed ethylene flames. Points are measurements and error bars denote a measurement uncertainty of $\pm 30 \%$ [54]. Solid lines correspond to the reversible PAH model and dashed lines to an irreversible PAH model [35]. Dash-dot lines are numerical results from [20]. 


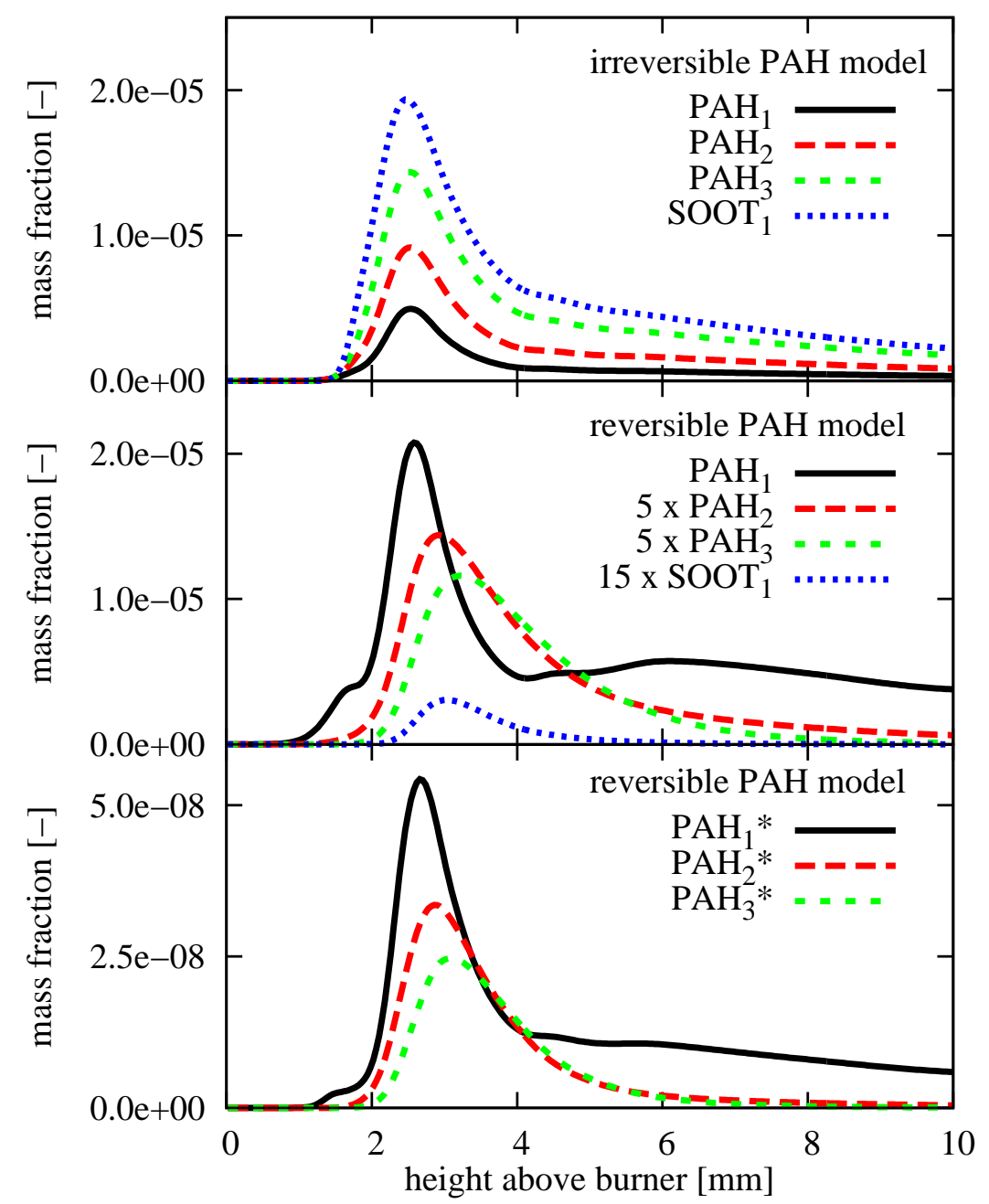

Figure 6: Predicted mass fractions of PAHs, $\mathrm{PAH}$ radicals and $\mathrm{SOOT}_{1}$ in a laminar premixed ethylene flame at $\mathrm{p}=1$ bar and $\phi=2.3$ [54]. Top panel: Irreversible PAH model [35]. Middle and bottom panels: Reversible PAH model.
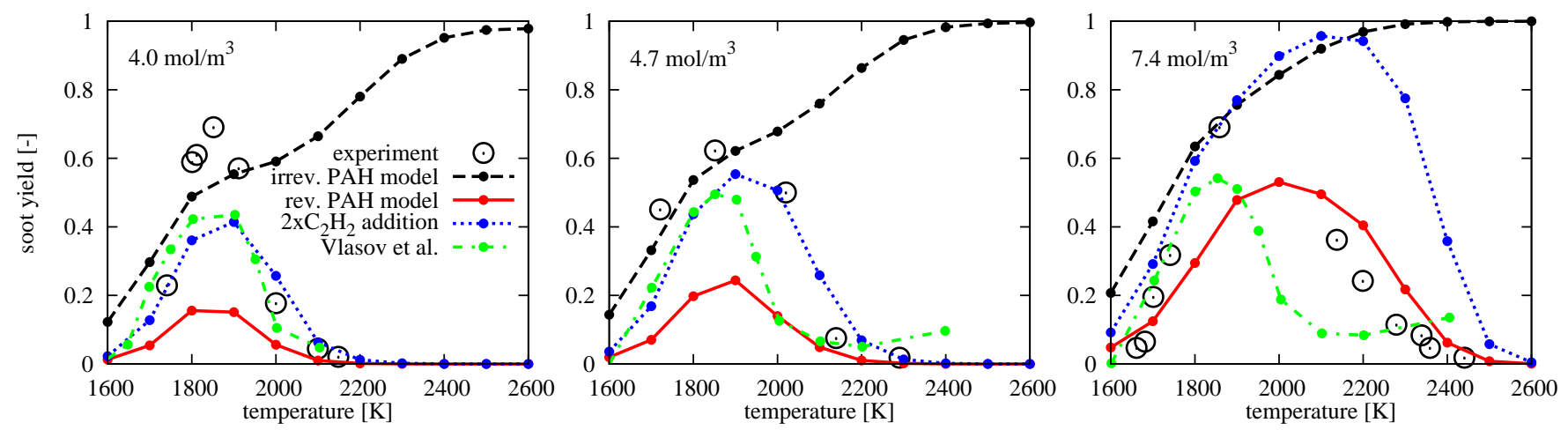

Figure 7: Measured and predicted soot yields in $\mathrm{C}_{2} \mathrm{H}_{4}$ pyrolysis after reflected shock waves for different carbon concentrations $\left(4.0,4.7\right.$, and $7.4 \mathrm{~mol} / \mathrm{m}^{3}$ carbon atoms in argon). Points are measurements from [67]. Solid and dotted lines correspond to the reversible PAH model. In the latter case the rate of surface growth by $\mathrm{C}_{2} \mathrm{H}_{2}$ addition was scaled by a factor of two. Dashed lines correspond to an irreversible PAH model [35] and dash-dot lines are numerical results from Vlasov and Warnatz [67]. 

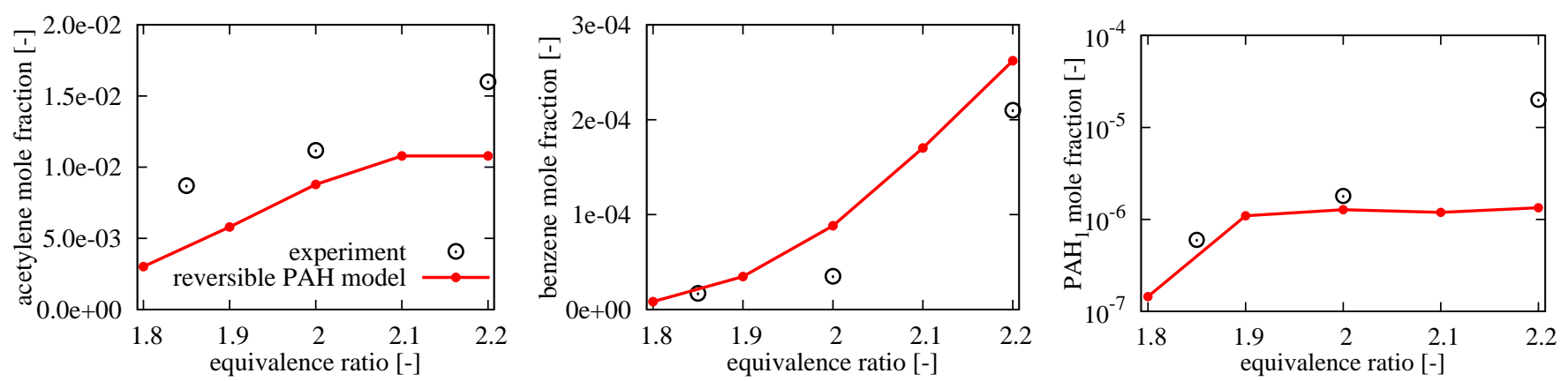

Figure 8: Predicted and measured species mole fractions in a PFR at different equivalence ratios. Lines are predictions using the reversible PAH model and open symbols are measurements from Manzello et al. 69].

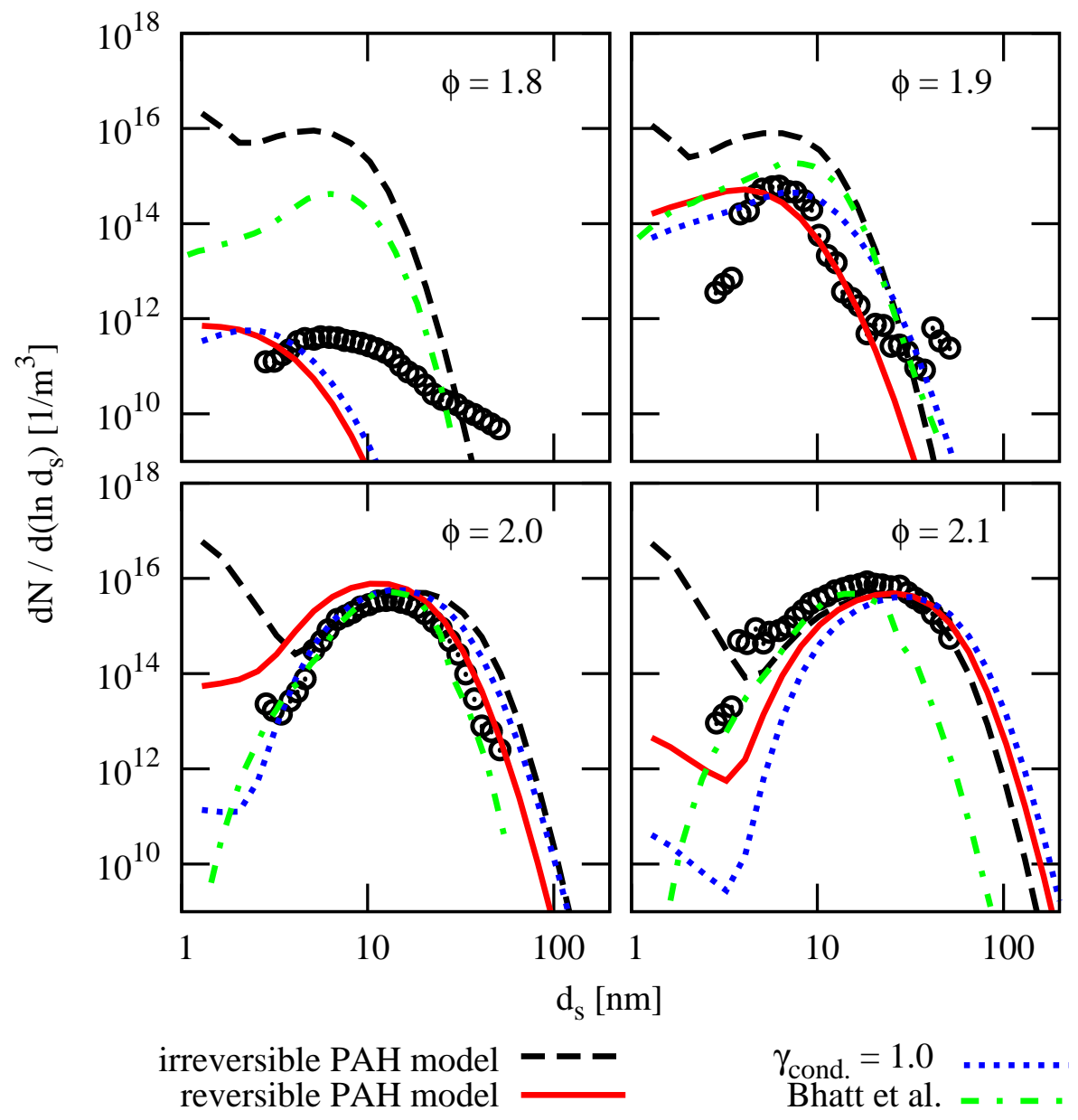

Figure 9: Measured and predicted soot PSD functions in a PFR at different equivalence ratios. Points are experimental data from Manzello et al. 69]. Solid and dotted lines correspond to the reversible PAH model. In the latter case the collision efficiency for PAH condensation was set to 1.0. Dashed lines correspond to an irreversible PAH model [35] and dash-dot lines are numerical results from Bhatt and Lindstedt [18]. 

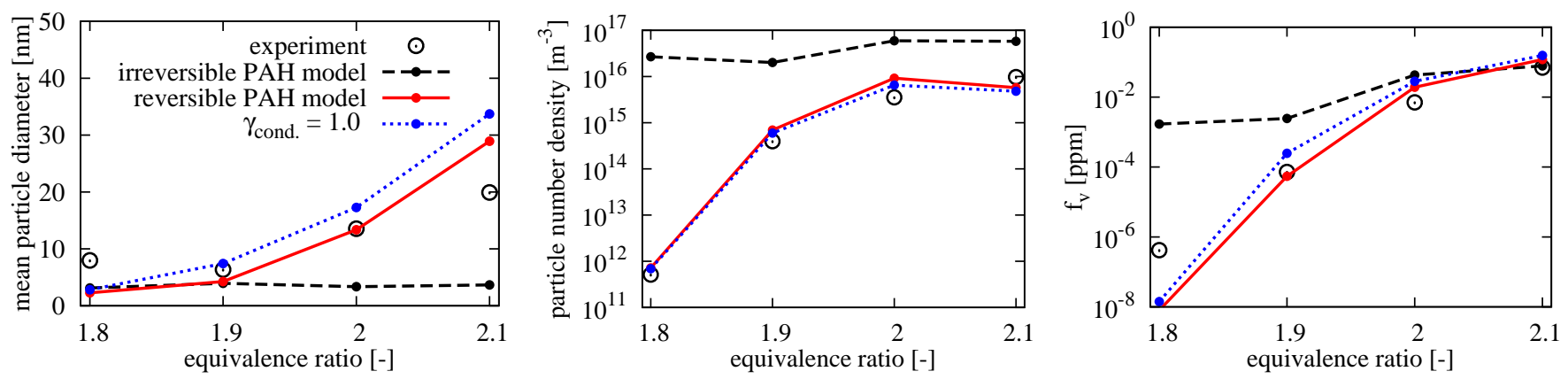

Figure 10: Predicted and measured soot properties in a PFR at different equivalence ratios. Points denote experimental data which was obtained by integrating measured PSD functions from Manzello et al. [69]. Solid and dotted lines correspond to the reversible PAH model. In the latter case the collision efficiency for PAH condensation was set to 1.0. Dashed lines correspond to an irreversible PAH model [35].
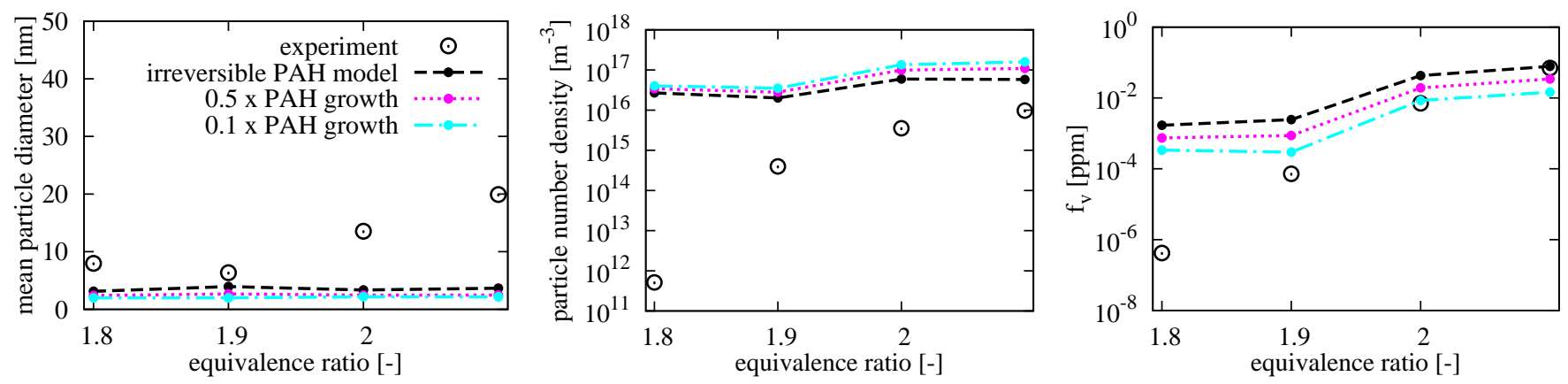

Figure 11: Predicted and measured soot properties in a PFR at different equivalence ratios. Points denote experimental data from Manzello et al. [69]. Lines correspond predictions using an irreversible PAH model [35]. In case of the dotted and dash-dotted lines, the efficiency of PAH collisions and the rate of $\mathrm{C}_{2} \mathrm{H}_{2}$ addition were scaled by the factors 0.5 and 0.1 . 